\title{
Electrification Beyond Light Duty: Class 2b-3 Commercial Vehicles
}

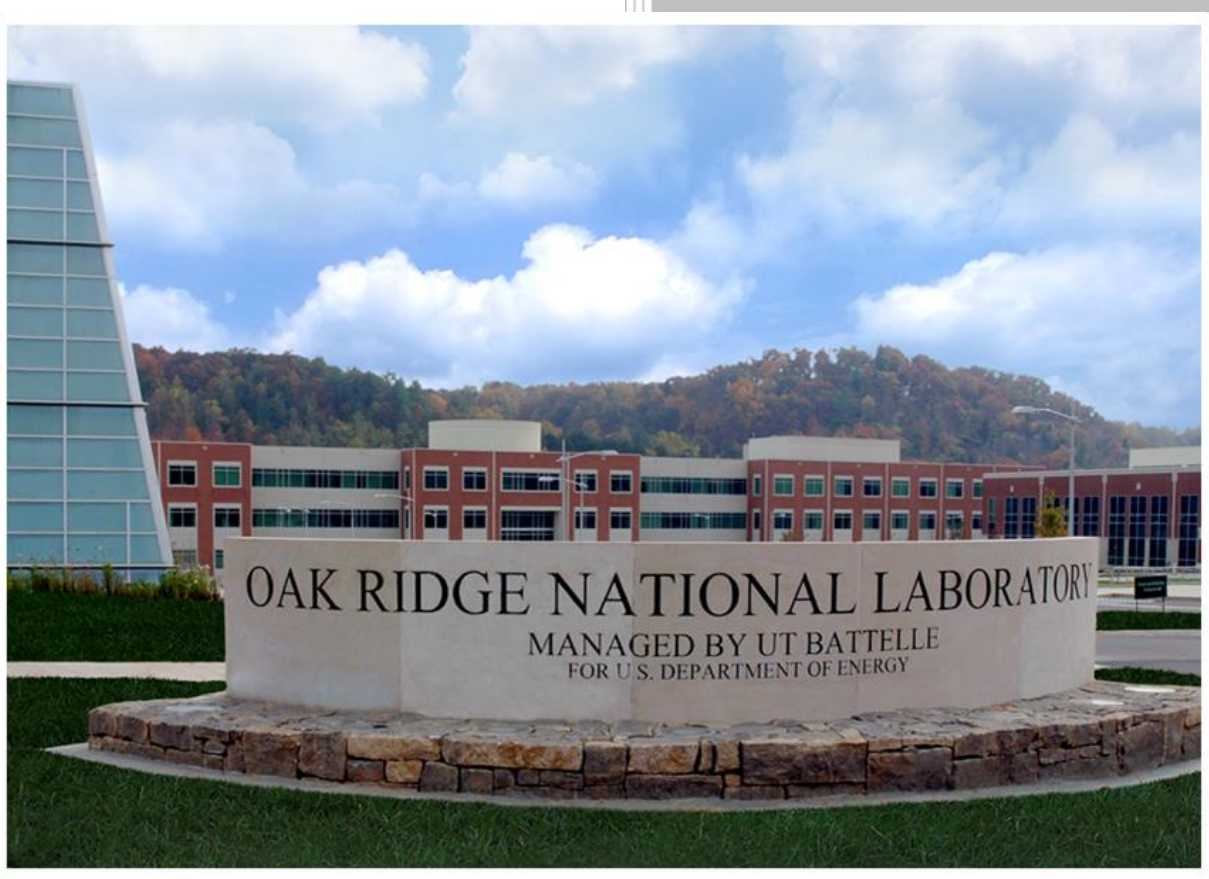

Alicia K. Birky

Michael Laughlin

Katie Tartaglia

Rebecca Price

Brandon Lim

Zhenhong Lin

December 2017 


\title{
DOCUMENT AVAILABILITY
}

Reports produced after January 1, 1996, are generally available free via US Department of Energy (DOE) SciTech Connect.

Website http://www.osti.gov/scitech/

Reports produced before January 1, 1996, may be purchased by members of the public from the following source:

\author{
National Technical Information Service \\ 5285 Port Royal Road \\ Springfield, VA 22161 \\ Telephone 703-605-6000 (1-800-553-6847) \\ TDD 703-487-4639 \\ Fax 703-605-6900 \\ E-mail info@ntis.gov \\ Website http://classic.ntis.gov/
}

Reports are available to DOE employees, DOE contractors, Energy Technology Data Exchange representatives, and International Nuclear Information System representatives from the following source:

Office of Scientific and Technical Information

PO Box 62

Oak Ridge, TN 37831

Telephone 865-576-8401

Fax 865-576-5728

E-mail reports@osti.gov

Website http://www.osti.gov/contact.html

This report was prepared as an account of work sponsored by an agency of the United States Government. Neither the United States Government nor any agency thereof, nor any of their employees, makes any warranty, express or implied, or assumes any legal liability or responsibility for the accuracy, completeness, or usefulness of any information, apparatus, product, or process disclosed, or represents that its use would not infringe privately owned rights. Reference herein to any specific commercial product, process, or service by trade name, trademark, manufacturer, or otherwise, does not necessarily constitute or imply its endorsement, recommendation, or favoring by the United States Government or any agency thereof. The views and opinions of authors expressed herein do not necessarily state or reflect those of the United States Government or any agency thereof. 
Energy and Transportation Science Division

Electrification Beyond Light Duty: Class 2b-3 Commercial Vehicles

\author{
Alicia K. Birky, PhD \\ Michael Laughlin, PMP \\ Katie Tartaglia \\ Rebecca Price \\ Brandon Lim \\ Zhenhong Lin, PhD
}

Date Published: December 2017

Prepared by

OAK RIDGE NATIONAL LABORATORY

Oak Ridge, TN 37831-6283

managed by

UT-BATTELLE, LLC

for the

US DEPARTMENT OF ENERGY

under contract DE-AC05-00OR22725 



\section{TABLE OF CONTENTS}

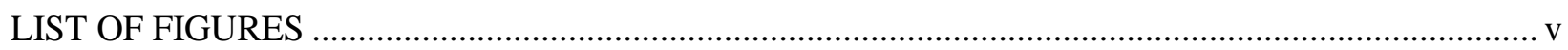

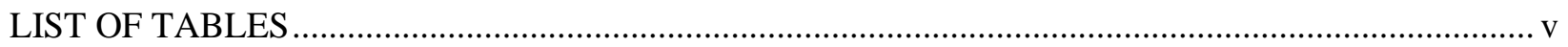

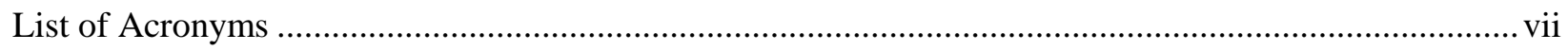

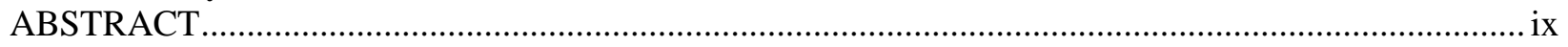

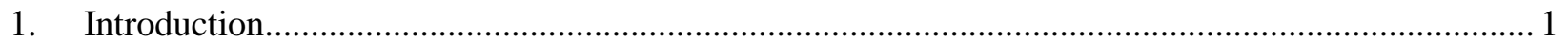

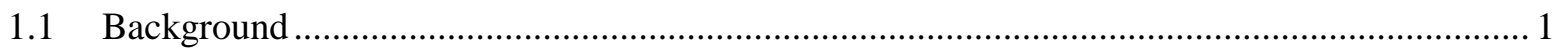

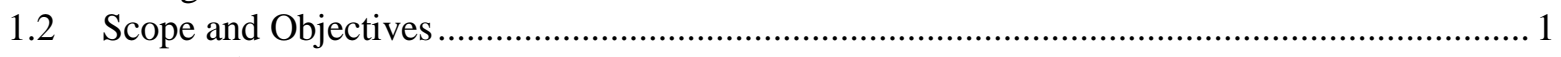

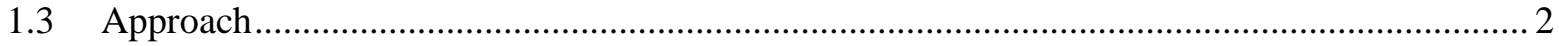

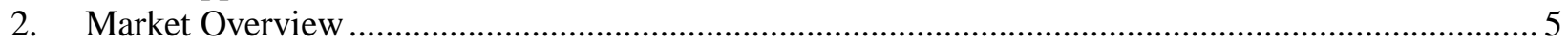

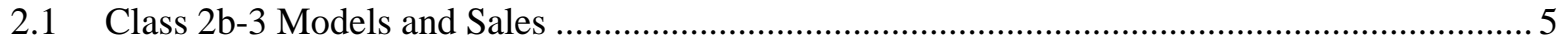

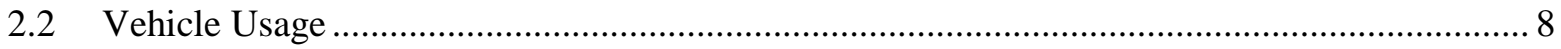

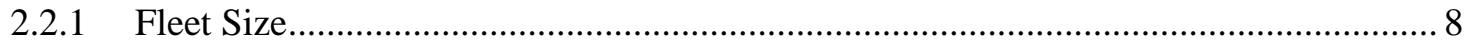

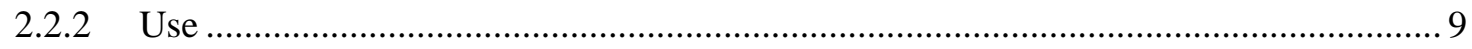

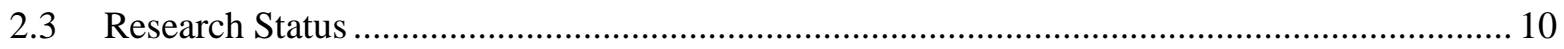

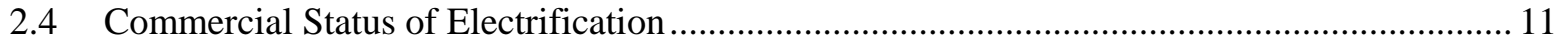

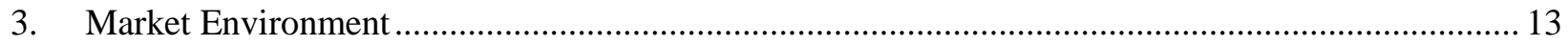

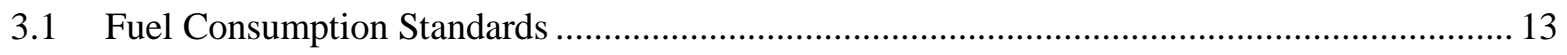

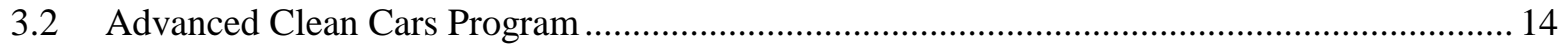

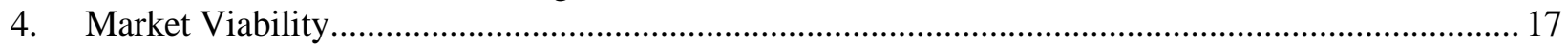

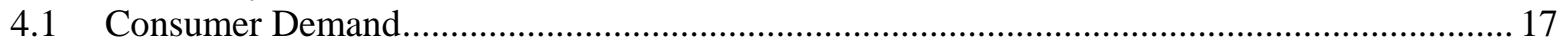

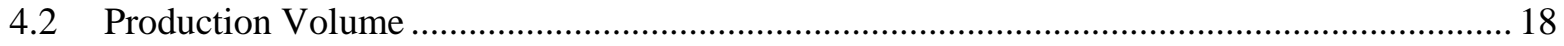

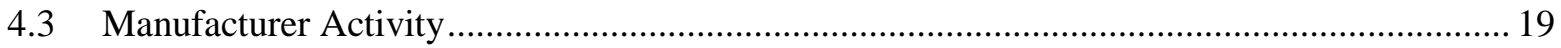

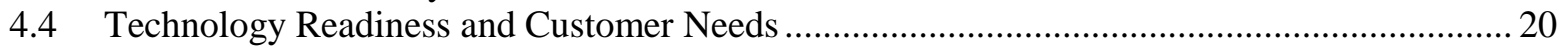

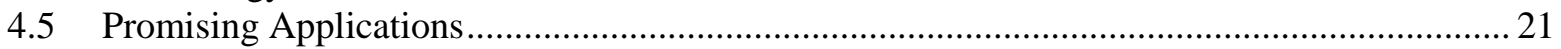

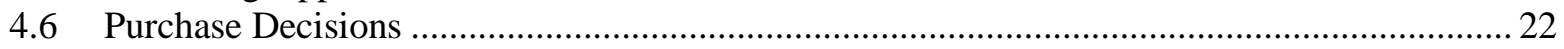

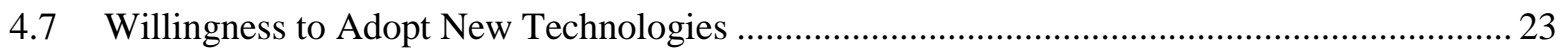

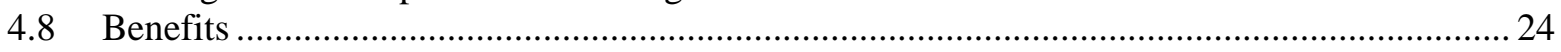

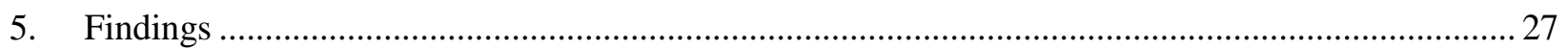

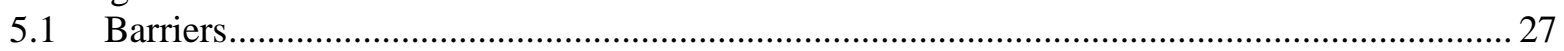

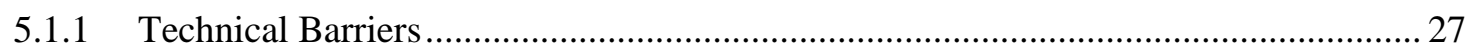

5.1.2 Economic Barriers ....................................................................... 28

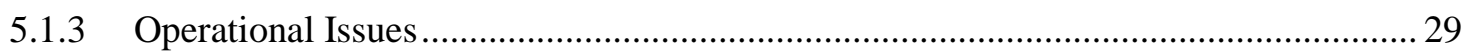

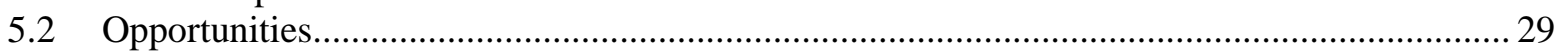

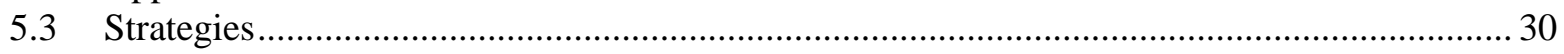

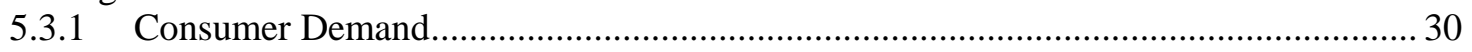

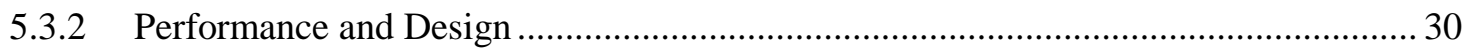

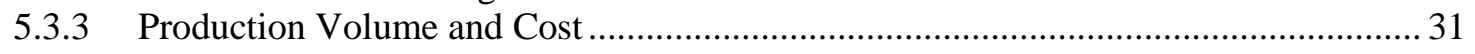

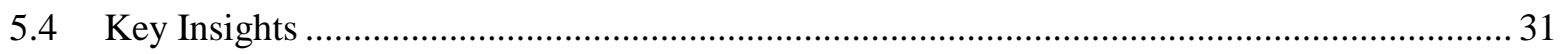

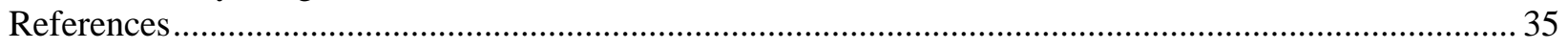




\section{LIST OF FIGURES}

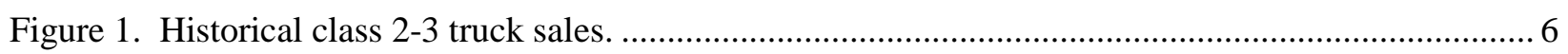

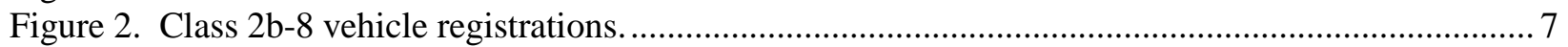

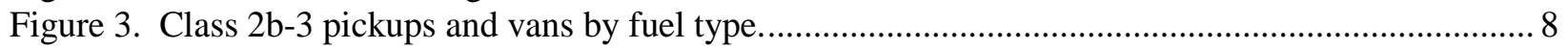

Figure 4. Fuel consumptions standards as a function of work factor.................................................. 14

Figure 5. Illustration of fuel consumption standard for class $2 \mathrm{~b}-3$ pickup trucks.................................. 14

Figure 6. Increase in mandated ZEV/TZEV sales through 2018 ...................................................... 14

\section{LIST OF TABLES}

Table 1. Example class $2 \mathrm{~b}$ vehicle models $(8,500$ - 10,000 lbs GVWR) .............................................. 5

Table 2. Example class 3 vehicle models (10,001-14,000 lbs GVWR) ................................................. 6

Table 3. Class 2-3 plug-in electric pickup and van models .............................................................. 12 


\section{LIST OF ACRONYMS}

ACC Advanced Clean Cars

ARRA American Recovery and Reinvestment Act of 2009

BEV battery electric vehicle

CAFE Corporate Average Fuel Economy

CARB California Air Resources Board

EPA Environmental Protection Agency

EPRI Electric Power Research Institute

GVWR gross vehicle weight rating

ICE internal combustion engine

kWh kilowatt hour

NHTSA National Highway Traffic Safety Administration

OEM original equipment manufacturer

ORNL Oak Ridge National Laboratory

PEV plug-in electric vehicle

PHEV plug-in hybrid electric vehicle

PTO power take-off

R\&D research and development

TCO total cost of ownership

TZEV transitional zero emission vehicle

VIUS Vehicle Inventory and Use Survey

VTO Vehicle Technologies Office

ZEV zero emission vehicle 


\begin{abstract}
The class $2 b-3$ truck market covers a wide range of commercial truck applications across a half-million vehicle sales annually. This report collected public information and stakeholder input to assess the opportunity for electrification in this market. Although class $2 b-3$ pickup truck and van bodies are very similar to personal light vehicles, their functional requirements are quite different due to the demands of the commercial market. These demands vary by application and often vary from day to day for a single application.

Fleet customers purchase these vehicles to perform a particular job for their business and are concerned about the overall cost of doing that job. Therefore, the vehicles must meet the job requirements cost effectively. Customers also are sensitive to initial cost.

Electrification offers the potential to reduce vehicle operating costs and possibly improve vehicle functionality. However, the current market for class $2 b-3$ electrified trucks is very small, and the trucks are costly. Increased production volumes are key to cost reductions and may be assisted by sharing components with larger or smaller truck classes. Expanding demand is also crucial and stakeholders identified several niche markets with duty cycles that are likely well-suited to electrified class $2 b-3$ trucks. To expand beyond these niches, class $2 \mathrm{~b}-3$ electric solutions must be robust, flexible, and adaptable in order to cover a wide range of vocations, applications, and duty cycles.
\end{abstract}




\section{INTRODUCTION}

\subsection{BACKGROUND}

Despite significant improvements in light vehicle fuel economy and criteria emissions, the U.S. transportation sector is still responsible for $70 \%$ of the nation's petroleum consumption. As a result, the sector is vulnerable to price fluctuations and supply disruptions and remains a significant contributor to local air pollution. Electrification presents one possible solution for petroleum consumption and emission reductions. While many electric technologies are commercially available in the light vehicle sector, there are fewer options in the medium and heavy duty commercial vehicle sectors.

Stakeholders at the April 2016 Electrification Beyond Light Duty Workshop identified commercial pickup trucks as an important market with little electrification activity. There are approximately 16 million class $2 \mathrm{~b}-3$ (8,501-14,000 lb GVW) pickups, vans, and vocational trucks currently registered nationally, with 13 million in class $2 \mathrm{~b}$ alone. ${ }^{1}$ These vehicles are widely used in large and small commercial fleets. Because class $2 \mathrm{~b}$ and 3 pickups and vans fall between light duty passenger vehicles and what typically are considered medium or heavy duty commercial vehicles (class 4-8), these trucks often receive little attention in government programs and policies, including data programs. Very little is published regarding the composition of this fleet, how they are used, how much fuel they consume, or how much they impact the environment. However, the U.S. Environmental Protection Agency (EPA) estimates that heavy-duty pickups and vans account for $23 \%$ of class $2 b-8$ vehicle fuel use (EPA \& NHTSA, 2016).

Electric drive options are very limited in the class $2 \mathrm{~b}$ and 3 market. Stakeholders at the workshop indicated that the heavy duty pickup truck market is risky for smaller companies since they would not be able to compete with potential future solutions from major original equipment manufacturers (OEMs). Therefore, they expect little movement in this segment unless the OEMs decide to act.

This study was sponsored by the U.S. Department of Energy's Vehicle Technologies Office (VTO) and Oak Ridge National Laboratory (ORNL). VTO and the national labs support research and development activities across a broad range of vehicles to improve the overall efficiency of the U.S. highway fleet. Electrification represents one technology opportunity for improving vehicle efficiency and reducing the cost of transportation petroleum dependence. The goal of this study is to add to the collective understanding of the electrification opportunity in the class $2 b-3$ market and to investigate barriers to electrification in this market. This study provides a qualitative assessment of the class $2 b$ and 3 market by combining information from public data sources, interviews with manufacturers and industry associations, and input from transportation experts.

\subsection{SCOPE AND OBJECTIVES}

This study investigates the feasibility and possible level of electrification for class $2 b-3$ commercial pickup trucks and vans. The scope of this research was limited to plug-in electric vehicles (PEVs), including battery electric (BEV) and plug-in hybrid electric (PHEV) vehicles. The scope limitations were not intended to imply preference for these technologies over others, such as hybridization without plug-in capability or fuel cells, and the authors acknowledge that alternatives can provide significant and possibly greater benefits in some applications. Much of the market and industry information presented here is relevant to other fuel saving and alternative vehicle technologies. This study seeks to identify applications and duty cycles most suitable for plug-in vehicle technologies and explore research gaps that could be

\footnotetext{
${ }^{1}$ Estimated number of trucks based on EIA analysis of 2014 Polk registration data for NEMS model inputs.
} 
addressed with future research and development investments. Stakeholder input was vital to identifying and understanding industry gaps, barriers, and opportunities.

\subsection{APPROACH}

This study consisted of two main tasks: a market assessment and collection of stakeholder input. The market assessment utilized publicly available information and data to characterize the market, the current state of electrification in that market, and the regulatory environment. Recent projects funded by DOE were reviewed to understand recent federal research and development activity. The study team identified and contacted stakeholders from manufacturers of class 2-3 heavy duty conventional and plug-in electric pickups and vans as well as industry associations. Stakeholders that expressed interest in providing their insights were engaged individually by phone and participated in free form discussions. In order to encourage candor, stakeholders were informed that their responses would be aggregated and that their comments would not be individually attributed. Input was received from a total of six stakeholders. Additional insights were obtained from public sources, including conference presentations, and the sources of these perspectives are attributed in this report.

While the participants were encouraged to lead the discussions toward whatever subjects they felt most relevant, the following list of questions was provided in advance to provide context and stimulate thought.

1. What are the most prevalent applications and duty cycles for these vehicles? Are Class $2 \mathrm{~b}$ vehicles used in different ways by customers than Class 3 vehicles? Is there any information you can provide on average fuel use per vehicle, operating weights, daily range, and average annual vehicle miles traveled?

2. Comparing use environment and duty cycle to light vehicles, what are the significant differences that would impact electric vehicle technology specification and design?

3. What typical payback periods do Class $2 b$ and 3 customers expect for new technologies in their vehicles? What other metrics, if any, do these customers use to decide whether or not to purchase new technologies? What main values drive purchase decisions?

4. Can you offer any insight on general rules of thumb for what production/sales volumes would be necessary in this market to achieve economies of scale / market sustainability in this market?

5. What is your view on electrification as a viable option in the Class $2 \mathrm{~b}$ and 3 market? (In this context, we are viewing "electrification" as a vehicle with plug-in capability and some all-electric range.)

6. Are there particular applications or niches within the $2 \mathrm{~b}$ and 3 market that would be good opportunities for electrification, and why? Any niches that would not be well-suited to electrification?

7. What has your experience been to date with electrification in the Class $2 \mathrm{~b}$ and 3 market? Have the vehicles been well-received by fleets and drivers?

8. What would you see as the major benefits of electrification for this market? (Efficiency, exportable power, idling reduction, etc.)

9. What would be the major barriers to success of electrification in this market? Technical, market/economic, customer acceptance, etc.? 
10. Are there technical or cost gaps that federal research can address to make electrification more viable in this market? 


\section{MARKET OVERVIEW}

\subsection{CLASS 2B-3 MODELS AND SALES}

The Federal Highway Administration (FHWA) separates highway vehicles into eight size classes based on gross vehicle weight rating (GVWR). Class 2 is split into 2 a $(6,001-8,500 \mathrm{lbs}$ GVWR) vehicles, which are generally considered light duty and regulated for fuel economy as light duty vehicles, and $2 \mathrm{~b}(8,500$ 10,000 lbs GVWR). Class $2 \mathrm{~b}$ vehicles include heavy duty pickup trucks, sport utility vehicles (SUVs), and full-size vans, as well as some chassis cab trucks and cutaway vans at the upper limit of the weight class. Table 1 lists several examples of class $2 b$ trucks. In many cases, manufacturers of class 2 pickups and vans offer these vehicles in both $2 \mathrm{a}$ and $2 \mathrm{~b}$ versions. As a result, model names are not always sufficient to determine if a vehicle is classified as $2 \mathrm{a}$ or $2 \mathrm{~b}$.

Table 1. Example class 2b vehicle models (8,500 - 10,000 lbs GVWR)

\begin{tabular}{|l|l|l|}
\multicolumn{1}{c}{ OEM } & \multicolumn{1}{c}{ Model } & \multicolumn{1}{c|}{ Type } \\
\hline Chevrolet & Silverado 2500HD & Van \\
\hline Chevrolet & Express 2500, 3500 & Pickup \\
\hline FCA & Dodge Ram 2500 & Van \\
\hline FCA & Dodge Ram ProMaster 1500 & Van \\
\hline Ford & E-Series 350 & Pickup \\
\hline Ford & F-250, F-350 & Chassis Cab \\
\hline Ford & F-250, F-350 CC & Van \\
\hline Ford & Transit 150, 250, 350, 350HD & Chassis Cab / Cutaway Van \\
\hline Ford & Transit CC / CA 150, 250,350, 350HD & Van \\
\hline GMC & Savana 2500 & Pickup \\
\hline GMC & Sierra 2500 & SUV \\
\hline GMC & Yukon 2500 & Van \\
\hline Mercedes-Benz & Sprinter & \\
\hline
\end{tabular}

Class 3 vehicles have a GVWR ranging from 10,001-14,000 lbs and include heavy-duty pickup trucks, vans, delivery trucks, box trucks, walk-in style vans, cut-away vans, chassis cab trucks, and stripped (bare) chassis. Table 2 lists example pickup and van models in this class as well as chassis cab and cutaway vans based on these platforms.

Three main manufacturers produce the majority of the available heavy pickup and van models: Chevrolet/GMC (General Motors), Fiat Chrysler Automobiles (FCA), and Ford. While registration and sales data are readily available for total class 2-3 trucks, few sources separate $2 \mathrm{~b}$ from $2 \mathrm{a}$ or pickup and vans from vocational trucks. As shown in Figure 1, sales of class 2 trucks reached 2.4 million in 2015 and have vastly outnumbered those of class 3 over the last three decades. However, class 3 sales have grown steadily over this period, reaching 283,000 in 2015 . 
Table 2. Example class 3 vehicle models (10,001-14,000 lbs GVWR)

\begin{tabular}{|l|l|l|}
\hline \multicolumn{1}{c}{ OEM } & \multicolumn{2}{c}{ Type } \\
\hline Chevrolet & Silverado 3500HD & Pickup \\
\hline Chevrolet & Silverado 3500HD Chassis Cab & Chassis Cab \\
\hline Chevrolet & Low Cab Forward 3500 & Chassis Cab \\
\hline Chevrolet & Express Cutaway 3500 & Cutaway Van \\
\hline FCA & Dodge Ram 3500 & Pickup \\
\hline FCA & Dodge Chassis Cab 3500 SLT & Chassis Cab \\
\hline Ford & E-350 Stripped Chassis & Stripped Chassis \\
\hline Ford & F-350, F-450 & Pickup \\
\hline Ford & F-350, F-450 & Pickup \\
\hline Ford & Transit 350HD & Van \\
\hline Ford & Transit CA / CC 350HD & Chassis Cab / Cutaway Van \\
\hline GMC & Sierra 3500 PU Regular & Pickup \\
\hline
\end{tabular}

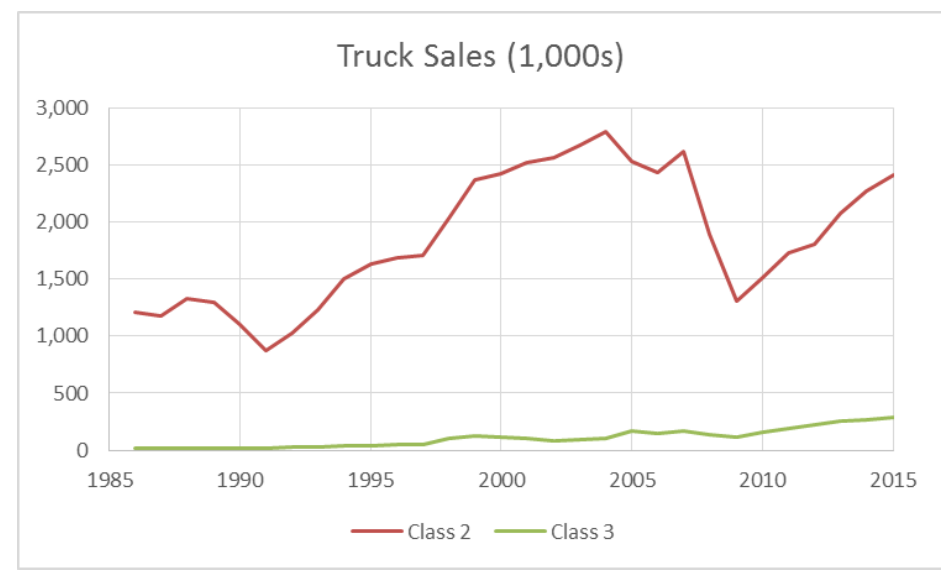

Figure 1. Historical class 2-3 truck sales.

Source: Davis, Williams, \& Boundy (2016) Transportation Energy Data Book, Ed. 35. Original source: Ward's Communication's, Motor Vehicle Facts and Figures, annual.

A number of factors have reportedly driven an increase the market for these smaller commercial trucks, particularly those powered by gasoline engines. Rising fuel costs over the past two decades have driven fleets to decrease fuel use and operating costs in general. The cost of diesel engines and diesel engine maintenance rose with the implementation of more stringent diesel engine emission standards in 2007 and 2010. Meanwhile, the fuel economy of gasoline engines has improved, closing the gap between gasoline and diesel engines. As a result of these pressures, fleets have moved from diesel to gasoline and downsized both engines and vehicles wherever possible. Meanwhile, OEMs have sought to improve the performance of smaller commercial vehicles and increase the models and options available. One notable recent development in this market is the introduction and increasing popularity of "Euro-style vans" such as the Ford Transit, Ram ProMaster, and Mercedes-Benz Sprinter. These front-wheel drive vans are available with both diesel and gasoline engines, are customizable, and offer increased fuel economy, lower floor height for easier loading, a tighter turning radius, and generally easier drivability. High-roof Euro-style vans are gaining popularity as mobile work centers because they allow the user to stand upright inside the van to perform necessary tasks. 
The majority of class 2 sales are 2a trucks. Based on analysis of IHS Polk registration data by the U.S. Energy Information Administration, about 400,000 class 2b and 140,000 to 170,000 class 3 trucks were sold annually between 2012 and $2014 .{ }^{2}$ Roughly $90-95 \%$ of class 2 b sales and $80-85 \%$ of class 3 sales are pickups and vans. This indicates total annual sales of class $2 \mathrm{~b}-3$ pickups and vans at about $475,000-$ $500,000 .^{3}$ While these numbers seem small in comparison to the 17.5 million light duty vehicles sold in 2015, they account for 55-60\% of all class 2b-8 vehicle sales as illustrated in Figure 2. Consistent with the registration data, the manufacturers who participated in this study reported that pickup trucks account for the majority of $2 b$ sales. The second largest sales volume in Class $2 b$ are "box removed" chassis cabs and cutaway vans that can be fitted with custom bodies.

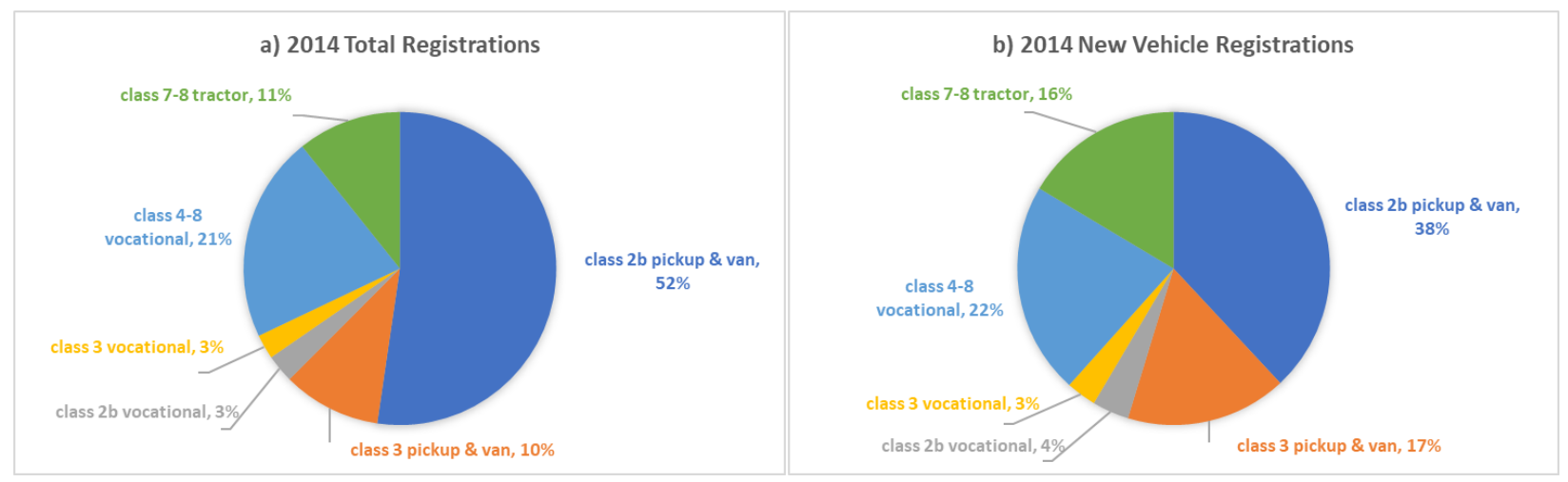

Figure 2. Class $2 \mathrm{~b}-8$ vehicle registrations.

Source: Energy Information Administration, NEMS input file for AEO 2016; analysis by Energetics Incorporated. Note: New vehicle registrations are vintage 1 in the NEMS input file as determined from model year.

Figure 3 shows the distribution of registered class $2 \mathrm{~b}-3$ pickups and vans by fuel type. Class $2 \mathrm{~b}$ accounts for $84 \%$ of heavy pickups and vans in use and $70-77 \%$ of sales. The fact that class 3 accounts for a higher fraction of sales than total registrations may indicate growth in class 3 relative to $2 b$. About two thirds of registered class $2 \mathrm{~b}$ pickups and vans are powered by gasoline or gasoline flex-fuel engines, one third by diesel, and a very small number $(<1 \%)$ by compressed natural gas $(\mathrm{CNG})$ and propane. Similarly, $62 \%$ of class $2 \mathrm{~b}$ sales are gasoline powered. The distribution for class 3 pickups and vans is reversed, with $72 \%$ of vehicles in use fueled by diesel and $28 \%$ by gasoline. Sales of class 3 pickups and vans are less heavily skewed toward diesel at $62 \%$, possibly indicating a shift toward or growth in gasoline vehicles.

\footnotetext{
${ }^{2}$ Annual sales by model year based on registrations. When compared to

Figure 1, these values imply that $2 \mathrm{~b}$ trucks represent about $20 \%$ of class 2 ; however, the data are not directly comparable since Figure 1 represents calendar year rather than model year sales.

${ }^{3}$ These estimates are similar to sales of $3 / 4$ and one-ton pickups (422,236 in 2012 and 535,205 in 2013) reported by

PickupTrucks.com at http://news.pickuptrucks.com/2013/03/update-total-retail-fleet-2012-sales.html and http://news.pickuptrucks.com/2014/04/who-sold-the-most-pickups-in-2013.html.
} 


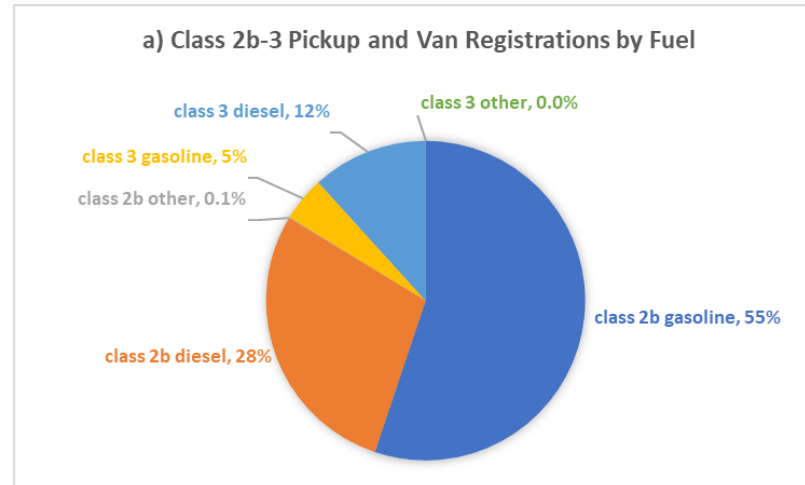

b) Class 2b-3 Pickup and Van New Registrations by Fuel

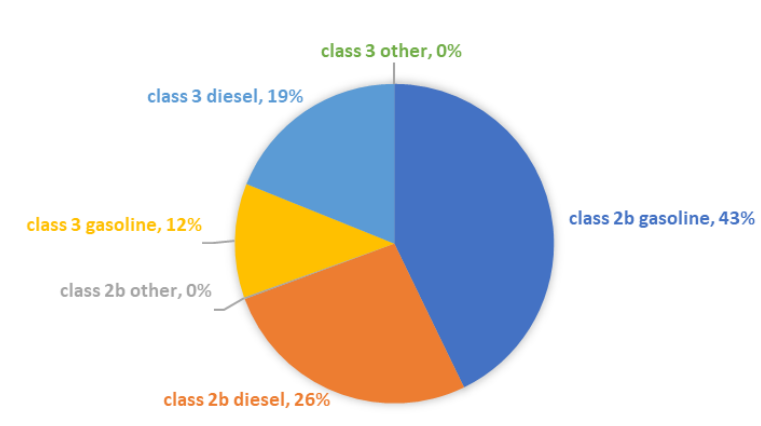

Figure 3. Class $2 \mathrm{~b}-3$ pickups and vans by fuel type.

\subsection{VEHICLE USAGE}

Class $2 \mathrm{~b}-3$ vehicles are used by both individuals for personal use and by businesses for commercial use. One stakeholder referred to this market class as "fleet-tail," indicating the combination of commercial fleet and retail sales in terms of ownership and usage. Unfortunately, there is no publicly available recent information on how these vehicles are used. ${ }^{4}$ Even registration ownership information can be misleading since small businesses and self-employed individuals may use privately registered vehicles for company business with reimbursement for mileage.

As discussed above, class $2 \mathrm{~b}$ vehicles include pickup trucks, some sport utility vehicles (SUVs), full-size vans, and chassis cab trucks, with pickup trucks accounting for the majority of sales. Vans and bare chassis trucks account for the second largest sales volume. Body up-fitters customize bare chassis trucks to provide work trucks, including dump, utility and service body, and tow and wrecker trucks, etc. Class $2 \mathrm{~b}$ vehicles are used for both personal (recreational, family, etc.) and commercial purposes. Stakeholders indicated that about half of class $2 b$ truck usage is for commercial purposes and half for personal purposes.

Class 3 vehicles include pickup trucks, vans, light dump trucks, flatbed trucks, dry bulk/tank trucks, and tow trucks. Class 3 vehicles also includes a few smaller light cranes and bucket trucks and other special purpose vehicles. As illustrated in Figures 2 and 3, there are fewer class 3 vehicles on the road than class $2 \mathrm{~b}$ vehicles. According to stakeholders, they also are more utilitarian and are more likely owned by businesses than individuals. Stakeholders indicated about $90 \%$ of these vehicles are used for commercial purposes.

\subsubsection{Fleet Size}

Industry analysts claim that larger fleets are more likely to take risks and adopt new technologies. Possible reasons are that these companies have better cash flow and more resources to invest; can test out a few vehicles in their fleet without impacting a significant portion of their operations; have employees dedicated to searching for potential cost savings; may have existing access to or the ability to construct their own fueling or charging infrastructure; and may have environmental sustainability initiatives and professionals on staff. Meanwhile, smaller fleets often buy the same type of vehicle over time and wait for larger fleets to test new technology and prove the benefits. This may be due to general risk aversion; a lack of resources to research new options and train personnel on the use, maintenance, and repair of new

\footnotetext{
${ }^{4}$ The Vehicle Inventory and Use Survey (VIUS), last performed in 2002, remains the most recent source of nationally comprehensive, public data on truck usage (annual miles of travel, trip distances, operating weight, etc.) (U.S. DOC, 2004). The sample size for pickups and vans in 2002 was extremely small and most industry experts feel this market has changed dramatically over the last 15 years.
} 
vehicles and technologies; and tight cash flow which results in the inability to survive disruption. For small fleets in smaller towns, technology choice may be constrained by what is available in the local market.

Class $2 \mathrm{~b}-3$ pickups and vans are found in a range of fleets across a wide variety of industry sectors. Stakeholders indicated that they are used as delivery and work vehicles for organizations of varying sizes from small family owned companies to large corporations. There were differing opinions among stakeholders on the proportion of vehicles used in small fleets compared to large fleets and some of these differences may represent differences in each manufacturer's market. One manufacturer reported that most $2 b-3$ customers were large delivery fleets. Another reported that the class $2 b$ customer base is roughly half large and half small fleets while the class 3 market is probably $60 \%$ large fleets. Another reported that as much as $75 \%$ of sales were used in small fleets of 2-10 vehicles.

Utilities and the telecommunications industry have a strong market presence in these classes and many of these entities purchase vehicles in relatively large quantities. However, one stakeholder reported that these purchases together account for less than $25 \%$ of class $2 b-3$ sales. Another pointed out that although one customer may buy a large number of one make and model, they will require multiple configurations, such as 2-wheel and 4-wheel drive, dual axle, extended and standard cab, power take-off (PTO) and powered equipment, export power, and other options. This makes the development, optimization, and production of electrified powertrains much more complex as multiple drivetrains may be required and sales volumes for each may be quite small. Delivery fleets represent another large market segment and companies use anywhere from a few to 500 cargo vans depending on whether the company is in an urban or rural setting. Municipal fleets are also significant customers.

\subsubsection{Use}

Stakeholders across the board stressed that the usage of class $2 b-3$ trucks is substantially different from light duty vehicles and covers a wide range of applications and usage profiles, with variation from company to company and day to day for any one company. The versatility of these vehicles is a major asset since many do not follow a set schedule, route, or duty cycle, and needs change from day to day. Another highly valued feature in this market is the ability to customize the truck with a body tailored to a customer's needs. One stakeholder called all of class 2-5 the "Swiss army knives" of trucks.

There is no single comprehensive data base of user applications, body upfits, or duty cycles, though some manufacturers may have data on how their vehicles are used. Several stakeholders acknowledged that their perspectives were based on a subjective understanding of anecdotal information. However, stakeholders agreed that most of class $2 b-3$ vehicles are used primarily for local driving. The vehicles are often kept at a central location, driven only a few miles away, and then returned. Many are used to transport work crews and equipment to job sites and the vehicles often are used as "tool lockers," carrying all the equipment or parts that may be needed on any given day. Average usage is about 15,000 miles per year, but this varies considerably, and larger fleets may see much higher mileage.

Idling is often a significant portion of the vehicle duty cycle, representing 30-50\% of in-use time for urban fleets while rural fleets see less idle and more mixed use. These trucks may be sold with only $30,000-40,000$ miles on the odometer but as much as 15,000 hours on the engine.

Stakeholders mentioned several specific applications for class $2 \mathrm{~b}-3$ pickups and vans, listed below, that demonstrate the wide range of uses. All of these applications have challenging characteristics that may make these less-desirable candidates for electrification. 
- Traffic duty, emergency, and road and other construction vehicles with short daily travel of 20-30 miles but high idle times. Many have a primary function that includes running safety lighting and flashers that require power while stationary for extended periods. These vehicles may also need to be capable of towing equipment to the work location.

- Emergency vehicles such as ambulances that are idled while waiting to be dispatched, often in the field, and require cab comfort (heat and air conditioning).

- Limos, shuttles, and taxis with continuous driving.

- Utility vehicles with short daily driving range, high idle time, and high demand for on-site power for cab comfort, mobile office equipment, and powered heavy equipment.

- Recreational vehicles with low annual mileage but high trip range.

- Short range, non-rural, hub-and-spoke delivery with consistent customers and routes, such as postal and parcel delivery.

- Short range service and delivery without consistent customers and routes, such as florists, catering, plumbing, etc.

- Class 3 trucks used for light commercial hauling and expedited shipping with daily round trips of 200 miles.

\subsection{RESEARCH STATUS}

PEVs can offer fuel cost savings compared to conventional vehicles but are more expensive to purchase at present due to the cost of the batteries and electric drive systems. The essential components of hybrid and PEV propulsion systems include electric motors, inverters, DC/DC converters, and on-board chargers. ${ }^{5}$ Increasing the adoption of electric drive technologies depends on improving the economics, particularly for commercial fleets who are sensitive to cost-benefit tradeoffs. National laboratories and industry partners have collaboratively pursued research and development (R\&D) to reduce the cost and improve the performance of innovative electric drive devices, components, and systems. This research addressed the cost, volume, and weight of batteries with $R \& D$ at the cell and module level through the investigation of new electrochemistries and materials. This research also targeted electric traction drive system cost, weight, volume, performance, and efficiency. This section provides a brief overview of recent R\&D related to commercial vehicle electrification. Because little work has directly focused on the needs of the class 2-3 market, this summary also includes light duty projects involving vans and SUVs. ${ }^{6}$

Plug-In Hybrid Medium-Duty Truck Demonstration and Evaluation Program: Sponsored by DOE using American Recovery and Reinvestment Act of 2009 (ARRA) funding, this program developed a path to migrate PHEV technology to medium-duty vehicles through the demonstration and evaluation of vehicles in diverse service applications. DOE partners included: the California Energy Commission, the South Coast Air Quality Management District, the Electric Power Research Institute (EPRI), Odyne Systems, Inc, VIA Motors, Inc., Southern California Edison, utility participants, and municipal industry

\footnotetext{
${ }^{5}$ The Alternative Fuels Data Center's pages on hybrid and plug-in electric vehicles provide a general overview of electric drive vehicles: http://www.afdc.energy.gov/vehicles/electric.html.

6 Additional information on DOE R\&D can be found on the EERE website: http://energy.gov/eere/vehicles/vehicletechnologies-office-plug-electric-vehicles-and-batteries.
} 
participants. $^{7}$ The program partners designed, developed, validated, produced, and tested a total of 296 PHEVs as well as a smart charging system. Production-ready PHEV systems include 119 Odyne Class 6 to 8 trucks, 125 VIA half ton pickup trucks, and 52 VIA three-quarter-ton vans (class 2a). Team participants gathered evaluation data during drive, charge, and stationary events in order to investigate performance improvement and cost reduction opportunities. The program was completed in July, 2015. Odyne and VIA are now producing vehicles developed under this program; the VIA vehicles are summarized in Section 2.4.

Advancing Transportation through Vehicle Electrification - PHEV: This ARRA cost-shared program supported FCA US LLC's light-duty electric drive vehicle and charging infrastructure-testing activities. Although the program did not involve medium duty vehicles, it supported development of related technologies for use in vans. The project team evaluated and demonstrated advanced PHEV technologies across a range of geographic, climatic, and operating environments in order to gain a better understanding of usage and operational needs. This allowed FCA to refine vehicle specifications that ultimately contributed to development of the Chrysler Pacifica PHEV, the first plug-in minivan available in the U.S beginning in MY2017. The project was completed in December $2014{ }^{8}$

Ford Plug-In Project: Bringing PHEVs to Market: This cooperative project was led by the Ford Motor Company in collaboration with the Electric Power Research Institute (EPRI), multiple utilities, the New York State Energy Research and Development Authority, and others. Company, demonstrated the feasibility of PHEV technology and improved the interface of the technology with the grid. Using MY 2008-2009 Escape SUVs, Ford developed 21 demonstration prototype PHEVs that were tested in project partner fleets. The project successfully demonstrated the feasibility of bi-directional Smart Meter communication with the electrical grid and supported EPRI's development of a fleet charging aggregator simulation tool to assess the potential for vehicle impact on the grid. Completed in 2014, the project results contributed to the introduction of two mass production PHEVs in North America, the Ford CMAX Energi and Ford Fusion Energi. ${ }^{9}$

Medium-Duty Urban Range Extended Connected Powertrain: This project is a collaboration between Robert Bosch LLC, Morgan Olson, NREL, the University of Michigan, and several other partners. The project goal is to achieve a 50\% reduction in fuel consumption for a class 4 delivery truck with a payback period of less than three years and an all-electric range of more than 35 miles. The team developed its plug-in hybrid vehicle powertrain design on electric drive components based on those for higher-volume light-duty vehicles. This project is still ongoing as of this writing, with completion in late 2019.

\subsection{COMMERCIAL STATUS OF ELECTRIFICATION}

As of the completion of this study, there are no class $2 b-3$ plug-in pickup truck models available for purchase in the U.S. However, Phoenix Motorcars and Zenith Motors offer BEV passenger (shuttle) and cargo vans and bare chassis trucks in this class. As shown in Table 3, both manufacturers install electric drivetrains on chassis purchased from major OEMs (Ford E350 and E450 and Ram ProMaster). VIA Motors produces class 2a PHEV pickups and vans based on GM platforms and is reportedly working toward a class $2 \mathrm{~b}$ offering. Two additional manufacturers have announced that they will be producing PHEV pickup trucks. Workhorse expects their class 2a pickup to be available in 2018 and will be the first

\footnotetext{
${ }^{7}$ Additional information is available at http://www.osti.gov/scitech/biblio/1234437-plug-hybrid-medium-duty-truckdemonstration-evaluation, https://avt.inl.gov/sites/default/files/pdf/phev/VTRUXPickupTruck.pdf, and https://avt.inl.gov/sites/default/files/pdf/phev/VTRUXVan.pdf.

${ }^{8}$ Additional information is available at http://www.osti.gov/scitech/biblio/1182581-advancing-transportation-through-vehicleelectrification-phev.

${ }^{9}$ Additional information is available at http://www.osti.gov/scitech/biblio/1133132-ford-plug-project-bringing-phevs-marketdemonstration-validation-project.
} 
electric vehicle manufacturer to produce their own pickup chassis. XL Hybrids is a major manufacturer of drivetrain systems as a Ford Qualified Vehicle Modifier for commercial hybrid vehicles (not plug-ins) and announced that they would be selling a PHEV pickup in the third quarter of 2017. Full specifications were not available for the XL Hybrids pickup which is based on a Ford F150 chassis, so it is unclear whether this will be a class 1 or 2a vehicle. In September 2017, Lightning Systems announced that it would introduce a BEV class 3 van on the Ford Transit platform in early 2018.

Table 3. Class 2-3 plug-in electric pickup and van models

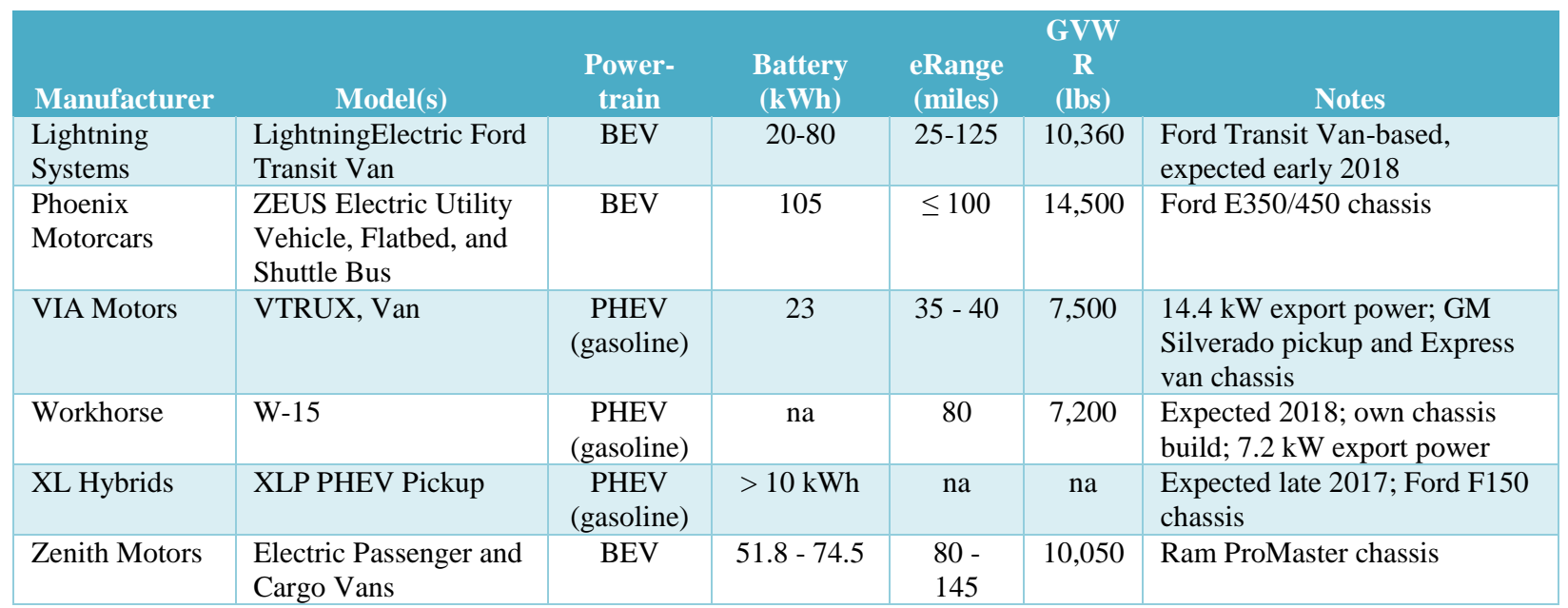

The Phoenix ZEUS and Zenith passenger vans are currently used in airport, hotel, and hospital shuttle bus fleets. However, there have been problems with drivetrain failures in the Zenith vehicles and the company has sued BorgWarner, the drivetrain manufacturer. Although the failed components were not subjected to loads above design tolerances and the drivetrain manufacturer was aware of their intended use in shuttle buses, stakeholders have speculated that the issue results from use of components designed for light duty vehicles. 


\section{MARKET ENVIRONMENT}

This section provides an overview of the manufacturing and sales environment for the class $2 b-3$ vehicle market in order to understand the challenges and potential opportunities presented. This environment has changed fairly rapidly over the past two decades and has affected how OEMs design, produce, market, and sell vehicles.

Despite their physical similarities to light duty vehicles, class $2 b-3$ vans and pickup trucks are considered commercial vehicles and are exempt from the light duty Corporate Average Fuel Economy (CAFE) standards authorized by Congress in $1975 .{ }^{10}$ The U.S. did not establish fuel consumption standards for medium- and heavy-duty vehicles, including commercial pickups and vans, until 2011. However, the OEMs that produce class $2 \mathrm{~b}-3$ pickups and vans also produce class 1-2a vehicles and the majority of the vehicles these OEMs produce are subject to the light duty CAFE standards. In addition, these OEMs are required to meet the requirements of the Advanced Clean Cars (ACC) Program established by the State of California in 1990 and more recently adopted by nine other states. Meeting these requirements has a direct impact on R\&D and product planning, which presents both barriers to and opportunities for the development of PEV options in class $2 b-3$.

This section provides an overview of the fuel consumption standards that apply to class $2-3(8,500-14,000$ lb GVWR) pickups and vans, as well as the ACC Program for light vehicles. This discussion serves as background for the stakeholder perspectives included in Sections 0 and 0.

\subsection{FUEL CONSUMPTION STANDARDS}

In 2011, the EPA and the National Highway Traffic Safety Administration (NHTSA) established the first fuel consumption standards for vehicles with GVWR above $8,500 \mathrm{lb} .{ }^{10}$ This Phase 1 Rule covered model years 2014-2018 (EPA \& NHTSA, 2011). In 2016 the EPA and NHTSA adopted a more stringent Phase 2 Rule that will be fully implemented by model year 2027 (EPA \& NHTSA, 2016). The fuel consumption standard for class 2b-3 pickup trucks and vans depends on fuel type (gasoline or diesel) and "work factor." The work factor is a linear function of payload and towing capacities and whether the vehicle is four- or two-wheel drive, with higher capacity vehicles having less stringent standards. The relationship between work factor and the fuel consumption standards, expressed in miles per gallon, is shown in Figure 4 for the beginning and ending dates of the Phase 1 (2014 and 2018) and Phase 2 (2020 and 2027) rules. ${ }^{11}$

\footnotetext{
${ }^{10}$ Beginning in 2012, the light-duty CAFE standards cover medium-duty passenger vehicles with GVWR between 8,500-10,000 $\mathrm{lbs}$, specifically sport-utility vehicles and passenger vans with less than a 13-person seating capacity.

${ }^{11}$ The fuel consumptions standards in gallons per 100 miles are an increasing linear function of work factor. Fuel economy (miles per gallon) is the inverse of fuel consumption, resulting in an asymptotically decreasing function as shown.
} 
4a) Diesel Standards

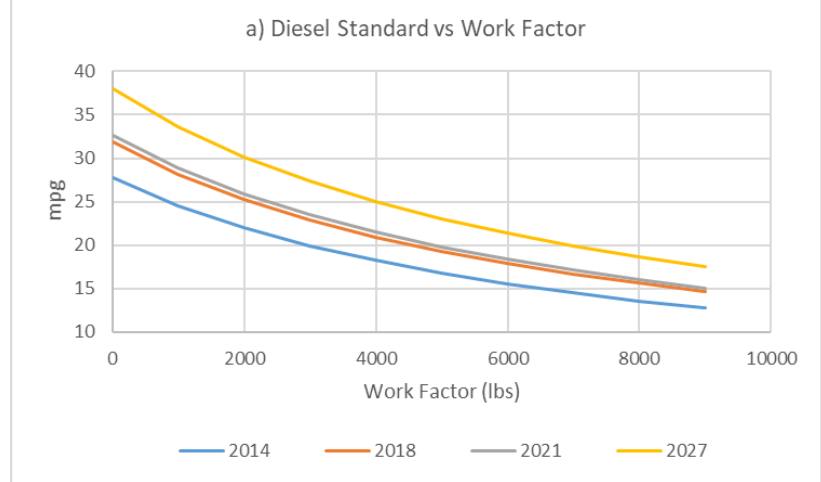

4b) Gasoline Standards

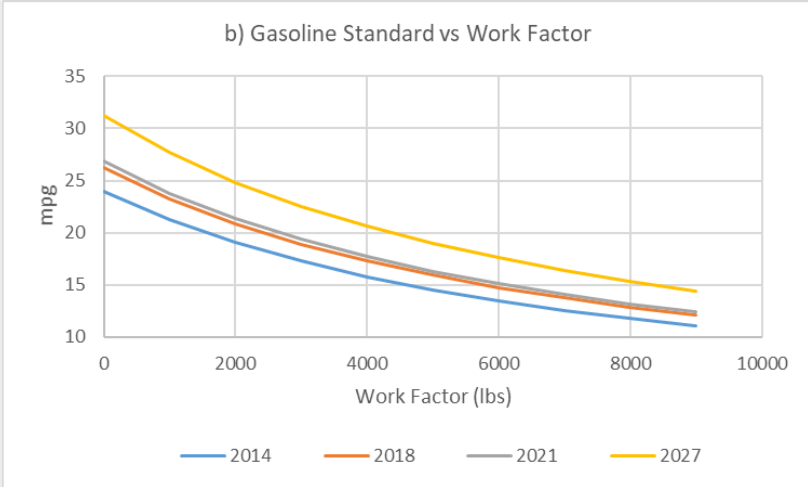

Figure 4. Fuel consumptions standards as a function of work factor.

The standard for gasoline vehicles represents a 9.3-9.4\% increase in fuel economy from 2014 to 2018 (Phase 1) and an additional 16.4-16.5\% from 2021-2027 (Phase 2), for a total increase of 30.5\%. The required improvement for diesel vehicles is higher at $14.9 \%$ in Phase 1, 16.4-16.5\% in Phase 2, and about $37 \%$ overall. The impact of these standards on class $2 \mathrm{~b}-3$ pickup trucks is illustrated in Figure 5 , based on typical 2016 vehicle specifications. It should be noted that graph presented is for illustration only since it assumes constant vehicle payload and towing capacities which may actually change over time.

4a) Diesel Pickup Models

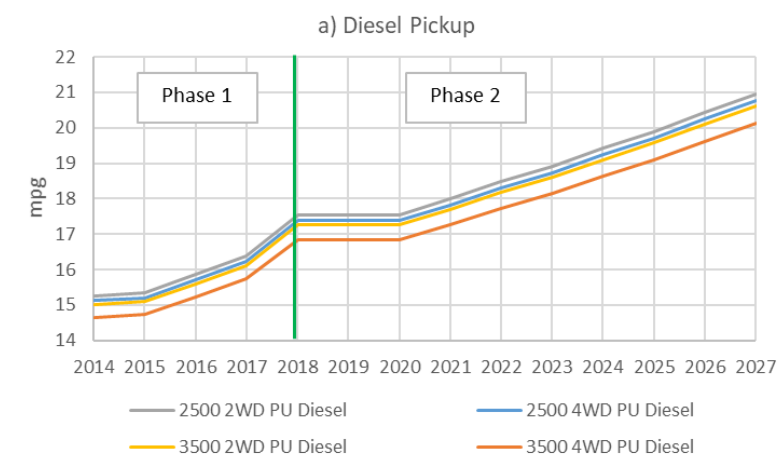

4b) Gasoline Pickup Models

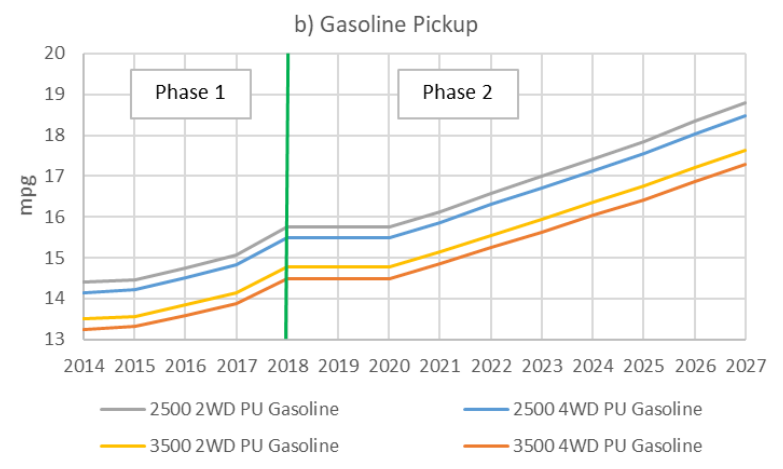

Figure 5. Illustration of fuel consumption standard for class $2 \mathrm{~b}-3$ pickup trucks.

\subsection{ADVANCED CLEAN CARS PROGRAM}

The California Advanced Clean Cars (ACC) Program requires that a percentage of light vehicle sales in California are zero emission vehicles (ZEVs) that emit no tailpipe emissions from the onboard source of power (such as BEVs and fuel cell vehicles), or Transitional Zero Emission Vehicles (TZEVs), which have no tailpipe emissions for some portion of their driving (such as PHEVs). As of 2017, nine states other states have also chosen to adopt the ACC Program: Connecticut, Maine, Maryland, Massachusetts, New Jersey, New York, Oregon, Rhode Island, and Vermont.

Minimum ZEV Floor - Portion of ZEV requirement that must be met with ZEV credits

TZEV Credits - Portion of requirement that may be met with credits from TZEVs

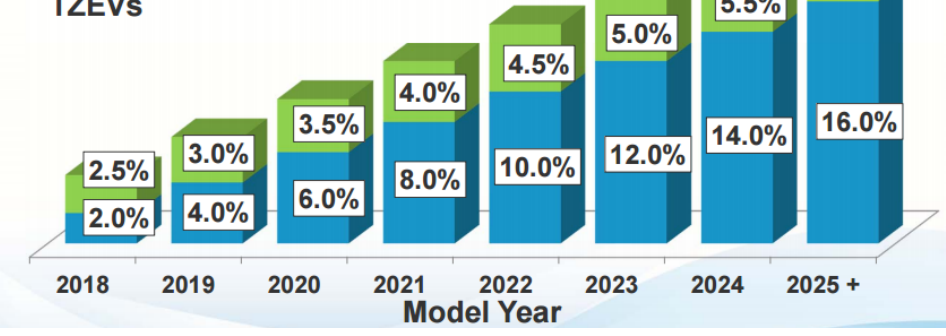

Figure 6. Increase in mandated ZEV/TZEV sales through 2018. 
Large vehicle manufacturers are required to meet a certain ZEV sales percentage depending on their average annual sales. ZEV sales are tabulated using a credit system (CARB, 2016), where between 1 and 4 credits are generated per ZEV sold based on the vehicle's all-electric range on the EPA city driving cycle. The sum of total credits earned through ZEV sales is required to be a certain percentage of the manufacturers' actual annual sales volume (CARB, 2016). Figure 6 shows the required credits as a percentage of sales for model years 2018 through 2025.

In addition to sales of ZEVs, credits can be earned by selling TZEVs or neighborhood electric vehicles, demonstrating advanced technology, and other measures. Since a single credit is not equivalent to a single ZEV sale it is difficult to exactly predict future ZEV market share, but about $15.4 \%$ of new vehicles sold in participating states will be required to be ZEVs by 2025 (CARB). Although the ACC Program currently only applies to sales of light vehicles, these requirements apply to the majority of the vehicles manufactured by the OEMs that also produce class $2 \mathrm{~b}-3$ pickups and vans. 


\section{MARKET VIABILITY}

The class $2 b-3$ market represents significant annual sales of almost half a million vehicles per year as noted above. The market is quite complex with multiple duty cycles, vehicle applications, and fleet customers, and at least some applications and customers would benefit from electrification if it were offered. This section explores the stakeholder feedback concerning the aspects of consumer demand, production volumes and economies of scale, manufacturer reluctance/willingness to develop electrified $2 \mathrm{~b}-3$ products, technology readiness and alignment with customer needs, the most promising applications for electrification, purchase decision drivers and processes, consumer willingness to adopt new technology, and potential benefits to the consumer.

At a high level, the stakeholders noted that consumers may not be willing to pay the additional cost for electrification and may not understand the utility of the technology. Production volume will be critical for reducing cost and increasing sales. This volume could come by exploring crossovers of electrification technology between the $2 \mathrm{~b}-3$ market and larger or smaller truck classes. Consumers are not interested in electrified $2 b-3$ trucks because of a lack of product, and small manufacturers are reluctant to enter the space because of potential competition from larger OEMs. There are several potential applications for both PHEV and BEV technology in this space. The customer is most interested in getting a vehicle that can perform the intended tasks and less interested in fuel economy. Finally, larger fleets are the ones more likely to adopt new technologies such as electrification.

\subsection{CONSUMER DEMAND}

Stakeholder feedback on the market demand for class 2b-3 PEVs was somewhat mixed. At least one OEM indicated that they had not seen any U.S. customer demand for hybrids or PEVs. They felt that, while a few environmentally focused customers might be interested, there would not be widespread adoption. Even if they could demonstrate an attractive financial payback, customers would reject the technology due to a reduction in cargo capacity resulting from reduced payload volume or increased vehicle weight. Other stakeholders reported that fleets, especially

Kev Findings - Demand

Consumers may not see the utility in the technology and may not choose it even if financials make sense.

- Market forces may result in unintended consequences with electrification (added weight, etc.) that may be counter-productive relative to overall goals such as reducing petroleum use.

- Consumers are often sensitive to initial capital cost and are not willing to pay for new technology. larger companies, have expressed a considerable amount of interest in electrification and in incorporating environmental sustainability into business practices. These stakeholders conveyed a general industry perspective that transportation electrification is not a passing trend but rather an inevitability and only a question of when and in which markets it will first occur. Manufacturers with international sales indicated that this was particularly true in Europe, noting that nearly all commercial vehicle manufacturers at the 2016 International Motor Show in Hannover, Germany, displayed commercially-available or concept PEVs. ${ }^{12}$ Stakeholders felt this activity was driven in part by proposals in several cities that would ban use of internal combustion engines (ICEs) within city limits as well as announcements by other countries of goals to eliminate use of ICE nationally.

\footnotetext{
${ }^{12}$ Known in German as the Internationale Automobil-Ausstellung (IAA, or International Automobile Exhibition), this show features passenger vehicles in odd numbered years and commercial vehicles in even numbered years.
} 
One stakeholder commented that electrification is the assumed solution for reducing emissions but may not be the best approach for all applications. Other technologies could reduce emissions, have less impact on the customer, and offer broader applicability. Examples of alternative solutions include improved combustion engines, idle reduction technologies, natural gas engines, hybrid electric powertrains, and other technologies. In addition, this stakeholder indicated that a push toward electrification in the $2 b-3$ class could potentially result in unintended consequences. For example, the added weight could shift vehicles up in weight class. If vehicle capabilities are reduced or only electrified options are available, there could potentially be a market shift toward larger class vehicles which would reduce emission benefits. This stakeholder stressed that the market is too complex for a "one-size-fits-all" solution and that the industry needs a technology that is non-intrusive, that equally benefits all players, and does not overly burden any one party.

While some fleet customers have expressed interest in PEVs, their willingness to pay appears to be quite low. One stakeholder indicated that utility fleets have expressed interest in PEV pickups since pickups constitute a large portion of their vehicle fleet. However, these fleets believed that a major OEM would be capable of producing the PEV at a much lower cost than an upfitter and they were only interested in purchasing PEVs if the cost was the same as or slightly higher than a conventional vehicle.

\subsection{PRODUCTION VOLUME}

Stakeholders identified achieving higher production volumes as a critical issue in market viability. VIA's final project report estimated component cost reductions of about $40 \%$ by increasing production to 3,000 units (Miyasato \& Kosowski, 2015). Stakeholders indicated that production for upfitters could be sustainable at 5,000 to 10,000 units per year. Sales around 10,000 units per year for 5 years would allow economies of scale and enable process improvements that reduce production costs, taking out as much as $45 \%$ of the small

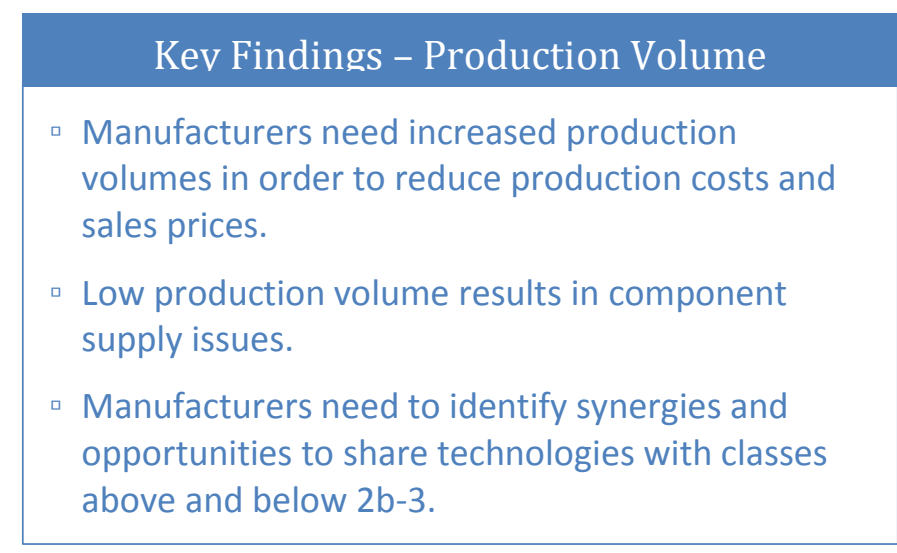
volume cost. The economics would be further improved if OEMs provided the chassis without the content (engine and transmission) that the upfitters remove. With this combination of factors and gasoline prices around $\$ 2.50, \mathrm{PEV}$ economics could be favorable.

Higher production volumes would be necessary for the market to be attractive to major OEMs. Success in the light vehicle market is measured at 100,000 to 200,000 units sold per year. A new introduction might be profitable if the first year sales are between 20,000 and 50,000 and the second year sees sustained growth. For major manufacturers that sell both light vehicles and heavy commercial pickups, it is difficult to justify sustained losses over 5 years without an indication of growing demand.

Stakeholders indicated that low production volume creates significant component supply issues. In the case where components or suppliers are common to light vehicles where production is relatively high, the suppliers charge higher prices to the low volume (commercial vehicle) purchasers and / or assign them low priority, resulting in delivery delays. When components are unique to commercial vehicles, manufacturers have even less market leverage with suppliers due to new and challenging design specifications. However, increasing production volume can be a double-edged sword in the early production phase when supply contracts may fix component costs based on first year volume. If 
manufacturers lose money on each vehicle sold in this phase, higher production volumes simply equate to higher losses.

Because of the relatively small commercial vehicle sales volumes in comparison to light vehicles, the ability to share components across classes is key to realizing cost reductions and technological learning, even for conventional vehicle technology. Electrification efforts for commercial vehicles have focused on heavier weight classes. Therefore, identifying any possible synergies with class 4-5 vehicles or those with a GVWR just over 14,000 lbs. would enhance the viability of class $2 b-3$ electrification. This could simultaneously take advantage of lessons learned and provide economies of scale in component technologies. The ability to spread costs over global product lines would also be beneficial. However, product preferences differ internationally. For example, while full size pickups dominate the U.S. market, midsize pickups are more prevalent globally. Differences in safety and emissions requirements further complicate designing for the global market.

\subsection{MANUFACTURER ACTIVITY}

As of the date of this publication, no major truck manufacturers are actively pursuing electrification of class $2 b-3$ vehicles. Smaller startup companies are manufacturing class $2 b$ 3 PEVs as upfits to volume OEM chassis, such as the class 3 shuttle and cargo vans and bare chassis trucks produced by Phoenix Motorcars and Zenith Motors and the class 3 van from Lightning. No manufacturers currently produce class 2b-3 PEV pickup trucks, though VIA Motors sells a class 2a PHEV pick-up and is reportedly working on a class $2 b$. XL Hybrids

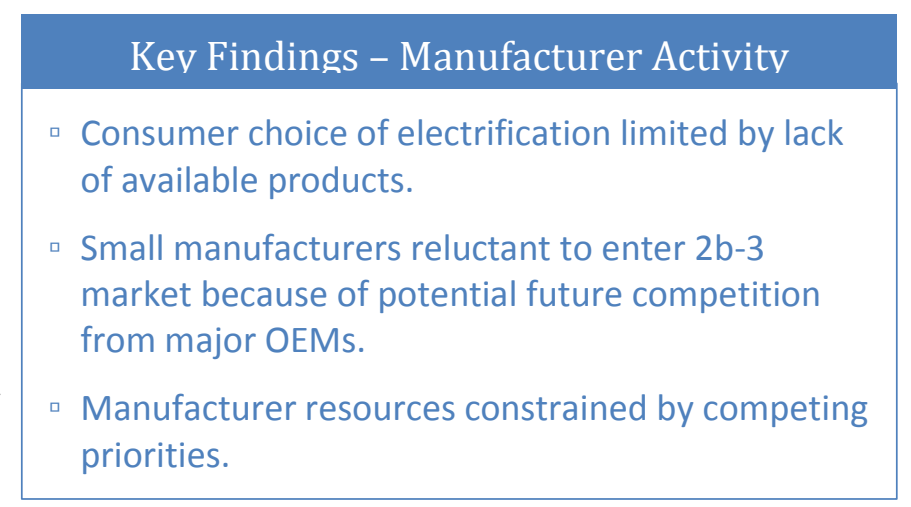
recently announced development of a PHEV based on the F-150 platform which may be class 2a. Workhorse is the only small manufacturer to announce development of a PHEV pickup (in class 2a) based on their own chassis specifically designed to be lightweight to accommodate the added battery weight of PEV applications. There has been much more activity with both manufacturers and fleets in integrating hybrid drivetrains rather than plug-in solutions, particularly in class 3.

Stakeholders indicated that manufacturers may be reluctant to enter this market due to possible future competition from major OEMs should they decide to build their own PEV solutions. Stakeholders also commented that, although PHEVs provide efficiency benefits relative to vehicles powered solely by gasoline engines, they compete with very efficient diesel engines and a diesel-electric PHEV would be a very expensive system. Therefore, for both efficiency and cost considerations, PHEV sypically incorporate a downsized gasoline engine. One stakeholder cited the lack of a smaller gasoline engine in their product lineup as a significant barrier to PHEV development.

Major OEMs may also face resource constraints posed by competing priorities. Fuel consumption standards for commercial vehicles became effective in 2014 and are increasing in stringency. Between 2014 and 2027, the fuel economy requirements for class 2b-3 pickups increase 30\% for gasoline and $37 \%$ for diesel trucks (EPA \& NHTSA, 2011; EPA \& NHTSA, 2016). Implementing PEV technologies may be one strategy to meet these standards, but this would require significant investment in product development. Meanwhile, these OEMs are also required to meet ACC Program requirements to develop and sell ZEV light vehicles in California and nine other states. They already have billions of dollars invested in development of light duty PEVs and, despite great technological achievements and cost reductions, sales remain low and the vehicles remain unprofitable. This makes it difficult to justify 
investment of several billion dollars to design a PEV pickup or van for an unproven market. Even if private or public funding were available, stakeholders indicated that they would not have the manpower necessary. Consumer expectations increase with each vehicle generation, requiring engineers to focus on performance. These major OEMs feel intense pressure to perfect the design of their light duty PEVs first. When the focus for light duty shifts to cost reduction, then the engineering effort could be turned toward new platforms.

\subsection{TECHNOLOGY READINESS AND CUSTOMER NEEDS}

While stakeholders generally believe there is a viable market for class $2 \mathrm{~b}-3 \mathrm{PEV}$, they indicate that current technology does not meet fleet needs. In order to make investments in PEVs, fleets need "ready-to-go" packages rather than vehicles that are still in the development phase. These perspectives echoed stakeholders' observations at the April 2016 Electrification Beyond Light Duty Workshop. Manufacturers indicated that commercial customers expected the purchase and use experience to be the same for PEVs as for conventional vehicles and that they became frustrated by supply delays and implementation issues.

\section{Key Findings - Technology Readiness}

- Consumers expect electrified vehicle purchase and use experience to be similar to conventional vehicles.

Consumers expect $2 b-3$ trucks to be flexible and adaptable to fleet needs and electrification solution must also be flexible.

- Current owners / operators generally are very happy with their electrified trucks.

Nearly all stakeholders stressed the need for a flexible solution that could be tailored to the needs of various applications and duty cycles. Operators view their trucks as tools; the ability to perform their required function is the primary factor in purchase decisions and class $2 b-3$ vehicles are valued for their flexibility to meet highly variable job demands. Current PEVs are upfits on conventional chassis, which can impact functionality. The added battery weight results in heavier vehicles and lower payload capacity, while the added components sometimes interfere with custom body and equipment attachment points. An ideal solution would involve a lightweight chassis, designed from the ground up for PEV needs, with modular battery packs, and attachment access points. Examples cited by stakeholders included a delivery vehicle with scalable battery packs and an extended range electric vehicle, $3 / 4$ or 1 -ton pickup.

At the same time, owner feedback to OEMs regarding PEV technology is almost always positive, as the technology has come a long way in the past 10 years. The VIA project sponsored by DOE, which concluded in July 2015, included a survey of vehicle operators to gain feedback on vehicle performance and driver satisfaction. Operating data for 151 vehicles show operation for a total of 16,220 hours and 82,520 miles over a period of 8 months. According to the final project report, fifteen operators responded to the survey and rated their overall satisfaction at 6.9 out of 10 (Miyasato \& Kosowski, 2015). They rated the vehicles highest on ease of driving (all modes) and charging at 8.3 to 8.5. The vehicles scored better on performance and "enjoyable to drive" in all-electric mode (7.1 and 7.8) compared to hybrid mode (6.9 and 6.8). Just over half (57\%) of the VIA van drivers stated that they would prefer the PHEV as their main work vehicle. ${ }^{13}$ The vehicle features that drivers most preferred included the all-electric mode, drive quality, and power / acceleration. When asked what features they would like to see improved, the drivers' largest concern was power when starting the vehicle on an incline. The respondents also

\footnotetext{
${ }^{13}$ Preference was not available from the pickup drivers.
} 
indicated the need to improve noise, throttle response and consistency, electric range, and ride quality. ${ }^{14}$ When asked why employers would consider using of PHEV trucks, the drivers most frequently cited improved fuel economy (100\%), reduced emissions (83\%), and reduced job site noise (50\%).

These observations are consistent with recent industry announcements. Based on customer feedback, VIA is reportedly working on a heavier PHEV pickup. Meanwhile, Workhorse is developing a PHEV pickup with a purpose-built chassis rather than an upfit on an OEM chassis.

\subsection{PROMISING APPLICATIONS}

Several stakeholders felt that class $2 b-3$ vehicles are a good fit for electrification, though not in all applications. Even in applications where electrification can work well, drivers may need to adjust their practices to accommodate range limitations and charging time. The following section summarizes stakeholder thoughts on where electrification likely would be viable and what technology would be best suited. However, stakeholders indicated that these impressions were based on anecdotal information and that actual usage data were necessary to determine the feasibility of implementing PEVs in any specific applications and how large that market might be.

Kev Findings - Promising Applications

- Consumers and manufacturers see electrification working well in some applications.

- The class 2b-3 market is complex, with trucks used for many duty cycles, and therefore requires flexibility.

- PHEV applications: duty cycle with short driving distance and need for job site power (e.g., utilities).

- BEV applications: duty cycle with regular routes including frequent stops and potential for opportunity charging.

As discussed in Section 2.2, stakeholders consistently emphasized the great variation in duty cycles for class $2 \mathrm{~b}-3$ pickups and vans among applications, among companies within industries or uses, from season to season, and from day to day for any one company or operator. As a result, these vehicles are valued for their versatility and flexibility for customization. Stakeholders felt that the most successful PEV for class $2 \mathrm{~b}-3$ would be a lightweight vehicle purpose-designed for electrification that could maintain cargo (volume or weight) capacity and retain custom body attachment points. Modular and scalable battery packs would allow fleets to customize the vehicles to their range and duty cycle requirements.

Many of the vehicles in this class are used in service industries and are driven short distances from the place of business or fleet yard to the job site, often in traffic. The job site often requires power for truckmounted or mobile power equipment, laptops, warning lights, and cab comfort that typically is provided by idling the vehicle's engine. This short range, stop and go, duty cycle can be ideal for PEVs, while exportable power can provide for jobsite needs. However, unpredictable job site demands can make battery sizing difficult, while inconsistent and remote destinations can make recharging difficult. Therefore, PHEVs may be an ideal solution for these applications. One stakeholder commented that the stop/start, engine-off at idle, and regenerative braking technology of hybrid vehicles has a proven value, delivering 20-30\% reduction in fuel consumption in urban environments, even without plug-in or allelectric driving capabilities. Applications for PHEVs identified by stakeholders include:

- Utilities and telecommunications

- Service providers such as landscapers, plumbers, electricians, and construction contractors

\footnotetext{
${ }^{14}$ It was not clear from the report whether the need for improvements in noise level were related to engine noise in hybrid mode or road noise in general.
} 
- Emergency response such as ambulances, police, traffic control flaggers

- Catering.

Stakeholders did identify some applications within the $2 b-3$ pickup and van market where BEVs would be technically feasible. These applications have duty cycles with frequent stops that take advantage of both regenerative braking and engine off at idle and regular routes with scheduled drop-off and pickup locations that might allow for recharging during the work shift. Ideally, these vehicles would also be lightly loaded or have decreasing load through the route, which reduces power demands when accelerating from a stop. BEVs could also be ideal for applications with a constrained service area where vehicles could take advantage of the short daily range, opportunities for recharging, and opportunities to install charging infrastructure. Stakeholders indicated that the ideal route would be around 36 miles. For urban routes, this would require a dependable, reliable BEV with a 50-60 mile range. Regular, scheduled routes could allow for two or three daily shifts with breaks for recharging. These short haul applications include:

- Local / regional parcel delivery

- Local / regional grocery delivery (baked goods, snacks, etc.)

- Ridesharing, where vehicles drive about 30-50 miles one way

- Passenger shuttles such as for churches, hotels, airports, and hospitals

- Military, government, or educational campus fleets.

\subsection{PURCHASE DECISIONS}

Stakeholders agreed that fuel economy generally is not the primary consideration of class $2 b-3$ customers in selecting a vehicle. Customers need a vehicle that is "the right tool for the job," so functionality and capability (e.g. cargo weight or volume capacity) are the primary considerations, along with safety. Meeting these needs is complicated by the high variability in duty cycle requirements across and within applications. Because job requirements vary from day to day and often involve varying job site power demands, fuel consumption is unpredictable. However, stakeholders indicated that all fleets worry about fuel consumption and that removing this worry is a major benefit of electrification.

Assuming that the vehicle under consideration is capable of meeting the job requirements, owners use a variety of approaches to make purchasing decisions. The approach used varies with fleet size, industry, length of ownership, and individual preference. Stakeholders identified the following considerations used by commercial vehicle buyers: upfront cost, payback period, return on investment, total cost of ownership (TCO), and unique vehicle features.

Service providers, such as plumbers and landscapers, constitute a large portion of class $2 b-3$ vehicle customers. These purchasers are mainly concerned with functionality and the financial bottom line. They typically are motivated by either price point or by fuel savings and payback. Customers with fixed budgets primarily consider upfront cost; adding safety and convenience at additional cost is not an option. Upfront cost may also be the primary consideration for applications where daily usage is highly variable and annual mileage or hours of usage are difficult to predict. 
Fleets with consistent duty cycles, such as delivery or passenger shuttles with fixed routes, can manage their fuel costs. These fleets may be more likely to use payback or return on investment for decision making. Customers that use payback for purchase decisions must justify the additional technology cost within their ownership period, even though the vehicles often have a "second life." Therefore, customers look for payback within 3-7 years. Stakeholders agreed that the ideal payback period was on the lower end of this range but disagreed on the upper bound, with one indicating 3 to 4 years and another 3 to 5 years. Companies with highly visible trucks, such as telecommunications companies, may replace their fleet relatively quickly (closer to 3 years) since the vehicle's visual appearance impacts the company's public image. Government fleets usually keep their trucks for 7 to 10 years, and other fleets as much as 12 to 15 years. In general, fleets that turn over their vehicles more quickly are more concerned about residual value than fleets that keep the vehicles longer. One stakeholder indicated that fleets that manage fuel costs and calculate payback or lifecycle costs estimate typical mileage at 15,000 per year, though the number can be drastically different for larger fleets and some specific commercial customers.

Purchasers that keep the vehicles longer are more likely to make decisions based on TCO and will consider fuel used per day, miles driven, idle time, maintenance, and insurance. Some of these owners will aim to keep the vehicle for the entire useful life of the chassis and replace parts and even the engine as needed. This is particularly true if the duty cycle includes more stationary idling, with little wear and tear on the chassis, versus driving long distances daily. These customers are concerned about battery replacement costs and the unknown complication and cost of maintenance for PEVs.

\subsection{WILLINGNESS TO ADOPT NEW TECHNOLOGIES}

Commercial vehicle customers generally are risk averse; their companies' profitability is directly impacted by the vehicles' ability to perform their intended function reliably and economically. Even if repairs are covered under warranty, owners incur opportunity cost from vehicle down time. Therefore, customers must have confidence in both the vehicle and the company from which they purchase it. This requires sufficient reliability and warranty coverage, but also a guarantee that maintenance and repair service will be

Key Findings - Adoption of Technology

- Commercial vehicle customers are risk averse and need confidence in the vehicle and in the company that makes it.

- Consumers need assurance that manufacturers will be in business to support vehicles over their lifetime.

- Larger fleets are more likely to be willing to adopt new technologies.

available over the life of the vehicle, wherever the vehicle is employed. This may be one reason that fleets often exhibit brand and model loyalty, purchasing the same vehicles over time.

One stakeholder pointed out that there is no lemon law for commercial vehicles, so customers bear the burden if the vehicle is unfit for its intended use or does not prove to be reliable and durable. ${ }^{15}$ In addition, federal law specifies required warranty terms for emission control equipment on vehicles with internal combustion engines and requires on-board diagnostics to ensure that the systems are working properly. ${ }^{16}$ BEVs are exempt from these requirements. As a result, environmental program managers and

\footnotetext{
${ }^{15}$ The Magnuson-Moss Warranty Act, or Federal Lemon Law, covers only vehicles used for personal or household purposes. State lemon law coverage varies and some states do cover commercial vehicles. The stakeholder that raised this issue manages a fleet in a state whose lemon law applies only to personal or household vehicles.

${ }^{16}$ For example, the EPA-established useful life for diesel engines used in class $2 b-5$ vehicles is 10 years or 110,000 miles. The mandated warranty on emission control equipment on these vehicles is 5 years or 50,000 miles, whichever comes first, but not less than the manufacturer's mechanical warranty for the engine.
} 
adopting fleets have no guarantee that BEVs will provide the lifetime benefits used to justify their additional costs.

Several stakeholders stressed the need to ensure that purchasers will be supported by a full service company and that they will be able to find parts to fix their vehicles after 5 or 10 years. Unfortunately, the history of commercial PEVs has been marked by the very visible failure of several manufacturers within a few years of product launch. Several of these companies used federal funds to successfully develop vehicles that were well received by customers. However, these manufacturers were unable to secure sufficient private funding to increase production levels and reduce costs to the point of profitability. Owners were left without service support. When a third party service provider offered to step in, they were denied access to proprietary information that would allow them to interpret on-board telemetry. This history increases the perceived risk of investing in PEVs.

Finally, stakeholders observed that larger fleets are more likely to adopt new technologies, while smaller fleets prefer to wait until the benefits and reliability of new technologies are proven by the larger fleets. Smaller fleets are also more sensitive to acquisition cost relative to larger fleets. Stakeholders indicated that larger fleets have the resources to be more innovative, while smaller fleets' resources are consumed by managing day to day business. As fleets grow, they are more likely to seek out opportunities presented by new technologies. Therefore, stakeholders expect slower adoption rates for PEVs in smaller fleets compared to larger fleets.

\subsection{BENEFITS}

Stakeholders provided their thoughts on the benefits to electrification from the perspective of manufacturers, fleet owners, and society. Some of these benefits are priced and are easily included in purchase decisions. Other benefits are not monetary or are difficult to quantify and therefore less easily incorporated in payback or cost benefit analyses.

Kev Findings - Benefits

Fuel cost reductions due to lower fuel price and idle reduction.

- Export power.

- Driveability and driver satisfaction.

- Societal benefits (petroleum dependence).

Fuel cost savings arising from favorable electricity prices and idle reduction were the most frequently discussed benefit of PEVs. Maintenance costs of BEVs theoretically are also lower than ICE vehicles since there are fewer moving parts in an electric motor than in a combustion engine, but there is too little information to confirm this assertion. However, no stakeholders cited this as a benefit and one indicated that the uncertainty of maintenance, repair, and battery replacement costs was a concern for buyers.

Although fuel economy often does not figure prominently in purchasing decisions, most fleets do worry about fuel costs and put considerable effort into managing them. Minimizing or eliminating this worry is a major benefit to electrification. Driver behavior has a significant impact on fuel consumption and driver training programs can reduce fuel costs. However, the driver often is not the vehicle owner and does not necessarily benefit directly from reduced fuel costs. Efficient driving incentives can be implemented, but lowering costs per mile with PEV technology gives fleet managers a bit more control. However, driver behavior is also an important factor in the efficiency and thus range of electric vehicles.

Many commercial vehicle operators need to meet job site power demands for truck-mounted and mobile equipment and cab comfort. These demands are either met by idling the truck engine or by using an auxiliary generator towed or hauled to the work site. Idling is particularly undesirable since it entails operating at a very inefficient part of the engine map where the specific fuel consumption and emission rates (grams per hp-hr) are high. PEVs with job site and export power can eliminate the need for an 
auxiliary generator and reduce or eliminate truck engine idling. Idle reduction reduces fuel costs, wear and tear on the vehicle engine, emissions of criteria pollutants, and job site noise. Reducing job site pollution and noise may improve the company's public image and may provide the opportunity for extended operating hours in the evening or overnight. Trucks with these features can also be used for emergency response in power outages, such as from major storms. Export power is a major selling feature for customers in utility, construction, and other service applications, and aftermarket systems designed specifically for job site power are commercially available and highly successful. Stakeholders commented that once customers have experience with the added features of job site and export power, the do not want to do without it.

PEVs offer a different driving experience compared to other vehicles and improve drive comfort and job satisfaction. Many hybrid vehicles save fuel by shutting the engine-off at idle during the drive cycle, but operators have complained about the rough transition at engine restart. PHEVs that use an all-electric launch mode eliminate this problem and provide a smooth transition from off-at-stop to start on motor. BEVs accelerate smoothly, operate quietly without vibration, and have no exhaust fumes. Stakeholders report that drivers much prefer the PEVs and report that they are not as physically tired at the end of a shift. One stakeholder stressed now nice it is to drive a "no fuss" ZEV. Quiet operation can enhance the vehicle functionality in many applications, such as providing utility, trash collection, and other services in residential neighborhoods, particularly at night, and border patrol or other law enforcement activities that benefit from stealth.

PEVs provide both public and private benefits by reducing dependence on petroleum. Historically, consumers have been subject to oil price fluctuations arising from market speculation, supply restrictions, supply disruptions from natural disasters, and other sources of price shocks. Fleets bear the cost of the difference between price at the pump and the actual cost to extract, refine, distribute, and market the fuel. For imported oil, the nation loses hundreds of billions of dollars annually in wealth transfer and lost or dislocated GDP. Stakeholders also stated that manufacturers suffer when vehicle sales by class or model shift in response to fuel price changes. By reducing petroleum dependence, a transition to PEVs would ultimately help OEMs with product portfolio planning. 


\section{FINDINGS}

This section focuses on the specific barriers identified by the stakeholders to more widespread use of electrification in the class $2 b-3$ market from a technical, economic, and operational standpoint. The stakeholders also offered some opportunities and strategies for overcoming these barriers that focused on reducing the cost of electrified drivetrains, increasing the confidence of purchasers around the technology, and increasing the production/sales volume of these drivetrains. The sections below outline these barriers and strategies and discuss potential opportunities for additional work.

\subsection{BARRIERS}

Stakeholders provided thoughts on barriers to greater production or adoption of class $2 b-3$ pickup and van PEVs. Their comments covered technical, operational, and economic issues from the perspectives of manufacturers and purchasers.

\subsubsection{Technical Barriers}

Technical barriers focus mainly on performance limitations, real or perceived, and design issues. The prominent technical issues arise from the high variability in duty cycles and routes in this class. This results in major concerns for operators regarding vehicle range. This variability, combined with the lack of complete and reliable usage and duty cycle data, also makes it difficult for manufacturers to determine design specifications. Accommodating the most demanding applications and alleviating range anxiety requires much larger batteries compared to light vehicles, adding both weight and cost. Additional loads at the job site, such as the need to run the air conditioner for cab comfort, further add to power and battery demand.

Current pickup and van PEVs options are upfits, resulting in expensive and heavy batteries incorporated on a platform that is already relatively expensive and heavy. Meanwhile, the manufacturer needs to keep the vehicle GVWR within the specified weight class, so the end result is a decrease in payload capacity and thus market viability. The added weight also causes design difficulties maintaining the proper distribution of weight on the axles and staying within the gross axle ratings. For these reasons, stakeholders indicated that a vehicle designed specifically as a PEV would have significant technical advantages over an upfit.

Stakeholders identified other perceived limitations that affect functionality and discourage adoption, including speed limiters, lack of torque, durability, reliability, and performance in extreme

temperatures. While many of these concerns are real design and manufacturing issues, others are misconceptions. For example, reliability has proven to be a real issue in some class 3 BEV shuttle vans. Many fleets cannot tolerate vehicle or battery failures during peak seasons when they earn much of their revenue and utilize their full capacity, such as package delivery fleets during November and December. On the other hand, lack of torque is not an inherent problem for electric vehicle technology. Electric drive provides full torque at zero motor speed while combustion engines have very low torque at low engine speed. This is the main reason that modern diesel locomotives use electric traction motors and many PEVs provide improved torque performance relative to conventional vehicles.

PEV drivetrains, installed as upfits to conventional chassis, also result in challenges for installation of custom bodies and equipment. OEM's have designed the vehicle and mounted all conventional components to the frame in a way that maximizes the opportunity to attach customized bodies. For some vehicle models, these attachment points have not changed in decades. Meanwhile, body upfitters have designed custom solutions for available attachment points so that no vehicle modifications are required. PEV components require considerable space and often interfere with these usual body attachment points, 
and new attachment points would require body builders to redesign their products and retool their facilities. Although it seems there should be plenty of space to add PEV components to a commercial vehicle, actual packaging is difficult.

While manufacturers have developed technically successful light duty PEVs and are approaching cost parity on a TCO basis, there are design challenges in translating this success to the class $2 b-3$ market by "scaling up" the components. First, commercial customers demand features not found on most of these light duty vehicles, such as all-wheel drive and export power. These features increase vehicle weight, power demands, and cost. The vehicles also see much higher mileage and hours of operation over their lifetime, sometimes accruing 200,000 to 300,000 miles then having the engines rebuilt and the vehicle returned to service. Many applications have significantly higher energy or power demands, such as heating and cooling for shuttle buses or powering aerial devices, PTOs, or other tools. While peak demand may be similar between light duty and class $2 b-3$, continuous demands may be much higher for commercial vehicles. In addition, integration of existing PEV components onto existing conventional trucks and using original drivetrain components (axles, transmission, etc.) does not provide an efficient or optimized design. System level engineering is required to take advantage of positive synergies and minimize negatives ones. Further, re-engineering specific components to be purpose designed would be preferred. Finally, because of the combination of higher energy storage demand, limited charging opportunities, and variable but potentially long daily range, commercial vehicles require faster, higher power charging.

\subsubsection{Economic Barriers}

Vehicle cost remains a significant barrier for class 2b-3 PEV market success, particularly as the efficiency of diesel engines improves. Many fleets that have expressed interest in PEVs and other advanced technologies, but are not willing to pay much extra for them. Many customers are sensitive to up-front costs and may not calculate the value of fuel savings, may heavily discount future cash flows, or may consider operating costs only in a qualitative sense. When customers do calculate payback, the added upfront cost may mean that they will need to purchase fewer trucks in a given year, which could mean operating older, less reliable trucks longer. Fleet managers may have difficulty justifying this down side when presenting options to upper management. For less investment, these customers may be able to realize some savings relative to a gasoline truck, and essentially no additional risk, by purchasing a diesel truck. The costs and benefits relative to diesel trucks most significantly affects PHEVs, which typically use a downsized gasoline engine since the cost of a diesel-electric PHEV would include the additional cost, relative to a gasoline truck, of the diesel engine and electric drive systems.

Battery cost is the most significant contributor to the incremental cost of PEVs, and stakeholders indicated customers are concerned about the unknown cost and frequency of battery replacement. Fleets that keep their trucks the longest, say for 12-15 years, may be concerned that there could be many battery replacements during their ownership period.

Some customers do use TCO, payback analysis, and return on investment, and might be likely to invest in PEVs once the business case is favorable. However, reducing production cost presents a major challenge for manufacturers, especially since they are still working to determine duty cycle requirements and improve the technology. One stakeholder noted that between generations of vehicles, customers' expectations regarding performance tend to increase, making it even more difficult to shift focus from performance improvements to cost reduction. Further, the major cost reductions required can only happen with an increase in production volume, which requires sufficient demand and adequate component supply. 


\subsubsection{Operational Issues}

Although PEVs are easy to drive, drivers must learn how to operate the vehicles to maximize the fuel savings. For BEVs, operators and fleet managers may need to make adjustments to driving habits and schedules to accommodate range limitations and take advantage of charging opportunities. The added burden of these issues or negative experiences with early implementation may discourage many fleet owners from purchasing the vehicles.

One stakeholder with experience employing BEVs called attention to additional challenges presented by charging commercial class $2 b-3$ vehicles. In many cases, the range of class 1 PEVs exceeds typical trip distances and level 1 or 2 charging is sufficient. Class $2 \mathrm{~b}-3$ PEV currently use class 1 , level 2 charging architecture, but energy demands are higher and charging opportunities are often shorter, resulting in longer time to restore a full charge. In addition, commercial fleets that need to recharge during the day face demand charges ${ }^{17}$ when charging time exceeds a threshold. For fleets with significant daytime charging needs, the added expense of demand charges can result in per mile operating costs that exceed conventional vehicles. Higher power charging would allow shorter charge times, simultaneously increasing operational time and decreasing demand charges. However, high power chargers require three phase, 480 volt electrical infrastructure, which may not be available and is expensive to install.

Many fleets perform vehicle maintenance services in-house. These owners are not familiar with PEV service needs and have concerns about the frequency and complexity of battery replacement and other maintenance. If these buyer's reluctance can be overcome, they still face the added cost of retraining their maintenance crews or the need to outsource these services. Buyers also have reservations about the reliability of the manufacturers and need assurances that the company will be around to provide these maintenance services for as long as they keep the vehicles.

\subsection{OPPORTUNITIES}

Current trends present some opportunities for early implementation of commercial PEVs that could lead to wider adoption. These opportunities represent applications where PEVs are well-suited and, in some cases, meet unique functional requirements that define a niche. In some cases, these niches provide a guaranteed market, such as fleet mandates. In other cases, because of unique market needs, consumers are willing to accept higher initial cost or lower performance on other functionalities not essential in that application. Although small, these niches provide protected market spaces that manufacturers may use to determine consumer needs, improve PEV performance, and decrease costs. Drivers and riders can simultaneously learn about PEVs' benefits and capabilities. Stakeholders identified the following potential niche markets for class $2 \mathrm{~b}-3$ PEVs.

The increasing popularity of ridesharing could provide an opportunity for PEVs since most trips are 3050 miles one way. Several ridesharing services recently announced the intent to implement shuttle type services with preset stops or suggested pickup locations, which could open this niche to class $2 \mathrm{~b}-3$ PEVs. Many facilities, companies, colleges, and even cities have established net zero strategies that include goals to consume only as much energy as produced onsite. College, government, airport, and business campuses that require on-site powered transport for employees, students, or customers are ideal application spaces for BEV shuttles.

Several European cities have proposed banning ICE vehicles within city limits. California has developed a plan requiring that all trucks and equipment serving the ports of Los Angeles and Long Beach ports be

\footnotetext{
${ }^{17}$ Electricity bills for industrial and commercial customers often include demand charges that are based on the customer's peak demand over a specified interval (typically 15 minutes) during the billing period.
} 
replaced with zero emission technologies. Zero emission zones may create a market for BEVs which operate over short range within the zone and for PHEVs which operate over longer distances but need the ability for ZEV operation within the zone.

Stakeholders also thought there might be an agricultural application for PEVs transporting farm workers and equipment to and within large farms.

\subsection{STRATEGIES}

Stakeholders offered suggestions on a number of potential strategies that would overcome barriers of demand, economics, and performance. Their comments included specific potential actions on the part of the major actors in this business space (manufacturers, upfitters, government agencies, and consumers).

\subsubsection{Consumer Demand}

Stakeholders conveyed a general industry perspective that electrification was inevitable and indicated that many larger fleet customers had expressed interest in the technology. However, they also identified several barriers to realizing sufficient consumer demand to create a sustainable market, including risk aversion, low willingness to pay, and concerns or misconceptions about vehicle capabilities and performance. Stakeholders mentioned a few possible strategies to overcome these barriers and several other strategies are suggested by their comments.

Taking advantage of opportunities to create market niches such as those described in Section 5.2 can be an important strategy for two reasons. First, several of the opportunities create a guaranteed demand (ZEV mandates, ZEV zones, and zero-carbon footprint programs) that would give manufacturers the confidence needed to continue investing in technology development and expansion of production. Manufacturers could partner with companies, municipalities, or institutions to gather usage and performance data as well as user feedback in order to improve vehicle design. Further, through positive exposure, these niche markets begin a process of consumer education that can overcome risk aversion and lead to increased customer acceptance.

Stakeholders indicated that is critical that class $2 \mathrm{~b}-3$ PEVs meet the customers' needs and be as reliable and durable as a diesel vehicle for the same useful life. Reliability concerns are amplified by a history marked by corporate failures and, in the case of BEVs, a lack of warranty requirements. Since diesel emission reduction programs constitute a primary early market for commercial PEVs, regulators could require the same warranty period for electric drivetrains as they do for diesel engines. Stakeholders at the Beyond Light Duty Workshop also suggested that manufacturers should have a plan to provide vehicle service in the event that the manufacturer fails.

\subsubsection{Performance and Design}

The high variability of applications and duty cycles presents several challenges for vehicle design, including the need to provide for maximum possible range requirements, allow for many features and configurations (AWD, extended cab, PTO, export power, etc.), maintain payload capacity (volume or weight), and accommodate custom body attachment. Stakeholders suggested several strategies to overcome these barriers while still achieving production volumes that allow manufacturers to reduce costs.

One possible approach would be to develop a single PEV configuration that meets the most common or most important features demanded by large fleets such utility companies. However, this might result in overdesigned vehicles for many uses. Therefore, several stakeholders indicated the need for a flexible 
platform that could be tailored to a variety of applications and duty cycles. An optimal approach would be a lightweight vehicle designed from the ground up for electrification rather than an upfit, thereby avoiding excess weight and interference with body attachment points.

Several stakeholders felt that PEV batteries need further development and one commented that it was difficult to obtain batteries that were packaged in a reliable way. Systems found on commercial vehicles, such as PTOs, have evolved over time to the point where they have similar capabilities and packaging across platforms. Applying this concept to the raw battery concept could have significant impact on battery performance, weight, and cost by improving power density and simplicity of fabrication. The stakeholder indicated that an ideal battery pack would be cell agnostic, allowing different and optimal chemistries for various applications. It would also be modular to allow both a range of capacities and different packaging of a single capacity in order to fit in a variety of vehicles while maintaining cargo volume and weight capabilities. A modular concept would also allow application across platforms to increase production volume and decrease cost. However, if this approach is technically feasible, significant investment would be required to develop the technology and put it into production.

In general, an optimal design would have a minimum number of components and attachments, whether the PEV is an upfit or designed from the ground up.

For upfits, stakeholders observed that it would be helpful if OEMs provided chassis without the drivetrain elements they needed to remove (engine and transmission). They also observed that it would be easier to install custom bodies if the electric drive system were "shrink wrapped," more modular, or could be located entirely under the hood. Otherwise, it is important for PEV upfitters to work with the body upfitters to ensure that integration is possible.

A few stakeholders remarked that product R\&D continues beyond initial demonstration of new and novel technologies. As much as $90 \%$ of the investment required to bring a technology to commercial production occurs after initial demonstration and includes design iterations required for durability and reliability.

\subsubsection{Production Volume and Cost}

Stakeholders discussed several strategies for increasing production volume in order to reduce costs and develop a sustainable market.

For upfits, strategies include arrangements with OEMs to provide chassis without components that the PEV upfitter would need to remove when purchasing a complete conventional vehicle. Other strategies include development of modular batteries and self-contained ("shrink-wrapped") electric drive systems. For a ground-up PEV design, stakeholders indicated the need for a flexible platform that could accommodate multiple configurations, features, and energy capacities.

The most consistently discussed strategy involves finding ways to share components across platforms within the weight class through development of a flexible and scalable system, or across weight classes by finding commonalities with class 4-6 PEVs.

\subsection{KEY INSIGHTS}

The table below summarizes the barriers and strategies from the previous sections and aligns them to illustrate opportunities and gaps for further study. As the table illustrates, the stakeholder strategies align well with the identified barriers. There appear to be strategy gaps for addressing the barriers of driver habits and actions, reduced fleet turnover, and collecting duty cycle data, however. This set of strategies is 
not intended to be exhaustive but rather a compendium of stakeholder inputs that will begin a discussion of how to encourage class $2 \mathrm{~b}-3$ electrification to meet consumer, manufacturer, and societal goals.

\begin{tabular}{|c|c|c|}
\hline \multicolumn{2}{|l|}{ BARRIERS } & STRATEGIES \\
\hline \multirow{7}{*}{ Technical } & $\begin{array}{l}\text { - Duty cycle variability and duty cycle data to } \\
\text { understand variability }\end{array}$ & \multirow{7}{*}{$\begin{array}{l}\text { - Develop modular and cell-agnostic battery } \\
\text { pack designs to apply flexibly across } \\
\text { platforms } \\
\text { - Share components across platforms by } \\
\text { finding commonalities with larger platforms } \\
\text { - Continue government investment in PEV } \\
\text { development to focus on continuous } \\
\text { improvement } \\
\text { - Create single PEV configuration to meet } \\
\text { common fleet needs on a flexible platform, } \\
\text { optimally designed from the ground up for } \\
\text { electrification }\end{array}$} \\
\hline & - Vehicle range - increased range requires & \\
\hline & $\begin{array}{l}\text { more batteries with more weight and cost } \\
\text { and decreased payload }\end{array}$ & \\
\hline & $\begin{array}{l}\text { - Scaleup of LD components - different } \\
\text { mileage requirements, different features } \\
\text { such as export power, etc. }\end{array}$ & \\
\hline & $\begin{array}{l}\text { Performance issues especially at high } \\
\text { ambient temperatures }\end{array}$ & \\
\hline & - Durability and reliability & \\
\hline & $\begin{array}{l}\text { - Interference of PEV drivetrains with body } \\
\text { and equipment installations }\end{array}$ & \\
\hline \multirow{6}{*}{ Economic } & $\begin{array}{l}\text { - Willingness to pay extra for electrified } \\
\text { technologies }\end{array}$ & \multirow{6}{*}{$\begin{array}{l}\text { - Create market niches to guarantee demand, } \\
\text { build production volume, and increase } \\
\text { customer acceptance (e.g. ridesharing) } \\
\text { - ZEV mandates } \\
\text { - Have OEMs provide upfitters with glider } \\
\text { chassis without drivetrains to reduce costs } \\
\text { - Develop modular and cell-agnostic battery } \\
\text { pack designs to apply flexibly across } \\
\text { platforms }\end{array}$} \\
\hline & $\begin{array}{l}\text { - Sensitivity to up-front costs and } \\
\text { undervaluing of future cost savings }\end{array}$ & \\
\hline & - Increased cost of electric trucks may mean & \\
\hline & $\begin{array}{l}\text { fleets purchase fewer trucks and keep older } \\
\text { trucks longer }\end{array}$ & \\
\hline & - Battery cost (initial and replacement) & \\
\hline & $\begin{array}{l}\text { - Reducing production costs by increasing } \\
\text { production volume }\end{array}$ & \\
\hline \multirow{3}{*}{ Operational } & $\begin{array}{l}\text { - Adjustments to driver habits and routes to } \\
\text { accommodate PEVs }\end{array}$ & \multirow{3}{*}{$\begin{array}{l}\text { - Utility work to address demand charges for } \\
\text { PEV charging } \\
\text { - Utility responsibility for engineering and } \\
\text { construction of power for infrastructure }\end{array}$} \\
\hline & $\begin{array}{l}\text { - Charging practices - frequency of charging, } \\
\text { demand charges for daytime, cost of higher } \\
\text { power fast charging }\end{array}$ & \\
\hline & $\begin{array}{l}\text { - Maintenance and repair - training for in- } \\
\text { house mechanics }\end{array}$ & \\
\hline
\end{tabular}




\section{ACKKNOWLEDGEMENT}

"The authors thank the U.S. Department of Energy Vehicle Technologies Office for funding support and project manager Dr. Rachael Nealer for technical support and guidance. The authors also thank the participating stakeholders for their invaluable insights and Dr. Zhiming Gao for his technical review and comments. The authors are solely responsible for the contents and views expressed." 


\section{REFERENCES}

CARB. (2016). California's ZEV Regulation for 2018 and Subsequent Model Year Vehicles. ZEV Tutorial Presentation. Retrieved from https://www.arb.ca.gov/msprog/zevprog/zevtutorial/zev_tutorial_webcast.pdf

CARB. (n.d.). Advanced Clean Cars Summary. Retrieved from California Air Resources Board: https://www.arb.ca.gov/msprog/clean_cars/acc\%20summary-final.pdf

Davis, S., Williams, S., \& Boundy, R. (2016). Transportation Energy Data Book: Edition 35. Oak Ridge: Oak Ridge National Laboratory. Retrieved from http://cta.ornl.gov/data/index.shtml

EPA \& NHTSA. (2011). Final Rulemaking to Establish Greenhouse Gas Emissions Standards and Fuel Efficiency Standards for Medium- and Heavy-Duty Engines and Vehicles, Regulatory Impact Analysis. US Environmental Protection Agency and National Highway Traffic Safety Administration, Office of Transportation and Air Quality.

EPA \& NHTSA. (2016). Greenhouse Gas Emissions and Fuel Efficiency Standards for Medium- and Heavy-Duty Engines and Vehicles - Phase 2. Federal Register, 81, 73478.

Miyasato, M., \& Kosowski, M. (2015, October 1). Plug-In Medium-Duty Truck Demonstration and Evaluation. Retrieved from U.S. Department of Energy Office of Science and Technical Information: http://www.osti.gov/scitech/servlets/purl/1234437

U.S. DOC. (2004). Vehicle Inventory and Use Survey 2002. US Department of Commerce, Economics and Statistics Administration, U.S. Bureau of the Census. Washington, DC: US Department of Commerce. 